\title{
Dos tumbas individuales calcolíticas en las inmediaciones de los dólmenes de Osorno y Simancas: estudio bioantropológico, ofrenda de perros y 'postvida' megalítica en el valle medio del Duero*
}

\author{
Two single graves from the Copper Age in the vicinity of the megalithic tombs of Osorno \\ and Simancas: bioanthropological analysis, dog offerings, and megalithic 'afterlife' in the \\ Middle Duero Basin
}

\author{
Germán Delibes de Castroa ${ }^{a}$ Ángel Esparza Arroyob, Javier Velasco Vázquez ${ }^{c}$, \\ Pilar Zapatero Magdaleno ${ }^{a}$, Carlos Fernández Rodríguez ${ }^{\text {, }}$ María Carbajo Arana , \\ Sara Palomo Díez ${ }^{\mathrm{e}}$ y Jesús Misiego Tejeda
}

\section{RESUMEN}

Con motivo de presentar dos tumbas individuales en fosa inéditas, se aborda un estudio de conjunto sobre las prácticas funerarias del Calcolítico Precampaniforme en la submeseta norte española. Pese a su carácter mayoritario en el registro arqueológico, se discute la representatividad como norma de este tipo de sepulturas; se rastrean comportamientos propios de rituales de enterramiento en dos tiempos, preludio de los documentados en este mismo espacio en la Edad del Bronce; se aporta información sobre el ADN mitocondrial y sexo molecular de uno de los difuntos, y se pone el énfasis, por vez primera en el Calcolítico de la cuenca del Duero, en el protagonismo de los perros en el mundo funerario. Por último, la proximidad de las dos nuevas sepulturas a sendos dólmenes - Los $\mathrm{Zu}$ macales (Valladolid) y La Velilla (Palencia)- da pie a debatir sobre el inicio de la 'postvida' megalítica en el valle medio del Duero.

\begin{abstract}
The authors examine two unpublished pits with single burials from the Spanish Northern Meseta dating to the PreBell Beaker Copper Age. Although such burials constitute the majority in the mortuary record of that time and place, we discuss the degree to which they are normative. We review the origins of the two-phased burial rituals, well attested in the area during the Bronze Age, the results of mitochondrial DNA and Y-chromosome analysis in one of the skeletons, and the importance of the often overlooked dog burials in the mortuary ceremonies of the Duero valley during the Copper Age. Lastly, the proximity of these two burials to the megalithic tombs of Los Zumacales (Valladolid) and La Velilla (Palencia) allow the authors to discuss the beginning of the 'afterlife' of these monuments in the middle Duero valley.
\end{abstract}

* Este trabajo ha sido posible gracias al Proyecto "Recursos, dieta y movilidad en las poblaciones del grupo Cogotas I" (HAR 2013-43851-P, financiado por el Plan Nacional I+d+i del Ministerio de Economía y Competitividad (IP: Ángel Esparza/Germán Delibes), que es coda de HAR 200910105, "Nuevos hallazgos y nuevas perspectivas en el estudio de los restos humanos del Grupo Cogotas I".

a Área de Prehistoria, Facultad de Filosofía y Letras. Unidad de Investigación Consolidada (UIC) Continuidad y cambio en la Prehistoria Reciente de la Meseta. Universidad de Valladolid. Plaza del Campus s/n. 47014 Valladolid. España. Correos e.: delibes@fyl.uva.es https://orcid.org/0000-0002-5553-6414; pilar_zapatero@yahoo.es https://orcid.org/0000-0002-8682-2798

b Dpto. de Prehistoria, Historia Antigua y Arqueología, Grupo de Investigación Reconocido (GIR) Estudios de Prehistoria de la Península Ibérica Universidad de Salamanca (PrehUSAL), Facultad de Geografía e Historia. C/ Cervantes s/n. 37002 Salamanca. España. Correo e.: esparza@usal.es https://orcid.org/0000-0002-9139-0774

c Área de Prehistoria, Facultad de Geografía e Historia. Universidad de Las Palmas de Gran Canaria. C/ Pérez del Toro 1. 35003 Las Palmas Gran Canaria. España. Correo e.: javier.velasco@ulpgc.es http://orcid.org/0000-0003-0339-3500

d Área de Prehistoria, Facultad de Filosofía y Letras. Universidad de León. Campus de Vegazana. 24071 León. España. Correos e.: cferr@unileon.es https://orcid.org/0000-0003-1739-1119;_mcarba00@estudiantes.unileon.es https://orcid.org/0000-0002-3353-4178

e Dpto. de Toxicología y Legislación Sanitaria, Facultad de Medicina. Universidad Complutense de Madrid. Plaza Ramón y Cajal s/n. 28040 Madrid. España. Correo e.: sarapalomodiez@med.ucm.es https://orcid.org/0000-0003-1559-2291

f Strato Gabinete Arqueológico SL C/ Encinar Parcela 29, Nave 1. 47193 La Cistérniga. Valladolid. España. Correo e.: strato@stratoarqueologia.es https://orcid.org/0000-0002-7099-3568

Recibido 25-V-2018; aceptado 7-X-2018. 
Palabras clave: Prácticas funerarias; Sepulturas en fosa; Edad del Cobre; Península Ibérica; Bioantropología; Ofrenda de perros; Muertos no enterrados; Enterramientos secundarios; 'Postvida' megalítica.

Key words: Mortuary practices; Pit-graves; Copper Age; Iberia; Bioanthropology; Dog offering; Unburied dead; Secondary burials; Megalithic 'afterlife'.

\section{INTRODUCCIÓN}

El propósito de este trabajo es presentar dos sepulturas individuales del Cobre Precampaniforme y analizar su problemática en el marco de la Prehistoria Reciente del valle medio del Duero. Una, la localizada en Osorno (Palencia), es rigurosamente inédita, a diferencia de la vallisoletana de Simancas, descrita a vuelapluma hace un cuarto de siglo, pero sobre cuya problemática hemos decidido volver con una documentación osteológica renovada. La primera fue descubierta en el transcurso de excavaciones de salvamento supeditadas a una gran obra pública, no así la otra directamente exhumada en una intervención de urgencia, después de sufrir grave mutilación durante el ensanchamiento de un camino.

Las sepulturas en cuestión, que revisten la forma de inhumaciones en fosa y que repiten el esquema de la mayoría de las calcolíticas conocidas en el interior de la península ibérica, constituyen una referencia de gran utilidad para el estudio en clave bioantropológica de la población y de las costumbres funerarias de la época. Además, proporcionan la oportunidad de revisar un tema tan sugestivo y lleno de simbolismo como el de la ofrenda de perros en las tumbas. Y, finalmente, aportan un muy ventajoso punto de vista para profundizar en el conocimiento del tránsito Neolítico-Edad del Cobre en el sector central de la submeseta norte, no en vano ambas tumbas, en cuanto a ritual funerario, se sitúan en las antípodas de los sepulcros megalíticos localizados en sus inmediaciones (Fig. 1).

\section{EL ENTERRAMIENTO DEL HOYO I-J/88-89 DE LA VELILLA, EN OSORNO (PALENCIA)}

\subsection{Situación}

Tanto por la plataforma cimera del otero que sirve de asiento al túmulo megalítico de La Velilla, dominando la vega del Valdavia, afluente del Pisuerga, como por su vertiente oriental se extiende un "campo de hoyos" cuya trayectoria cubre gran parte de la Prehis-

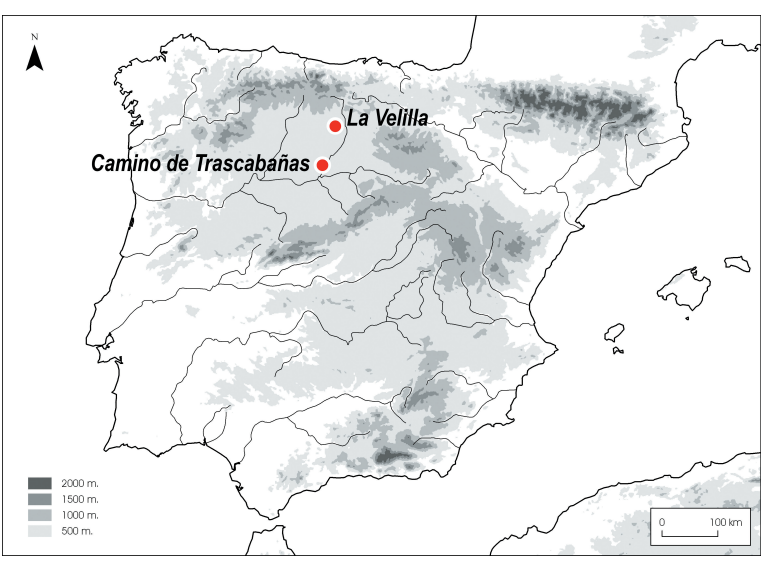

Fig. 1. Localización en la península ibérica de los enterramientos estudiados: La Velilla (Osorno, Palencia) y Camino de Trascabañas (Simancas, Valladolid).

toria Reciente. Algunos de tales hoyos, correspondientes al Neolítico Interior, fueron descubiertos hace una veintena de años junto al propio dolmen (Delibes y Zapatero 1996), y otros asimismo neolíticos, pero también de las Edades del Cobre y del Bronce han sido detectados a $350 \mathrm{~m}$ al SE de él, en el transcurso de la intervención arqueológica efectuada por la empresa Strato SL en agosto de 2006 como apoyo de las obras de la Autovía A-67 en su tramo Osorno-Provedo. El escenario de estos últimos trabajos se localiza al norte de la carretera P-240, de Osorno a Abia de las Torres, en un espacio $20 \mathrm{~m}$ por debajo de la cota del megalito y 10-15 por encima del río, cuyo centroide responde a las coordenadas UTM 385.788 X; 4.696 .769 Y (datum ETRS89= UTM 30) (Fig. 2).

Según la memoria técnica ${ }^{1}$, en la superficie intervenida, un rectángulo de $120 \times 40 \mathrm{~m}$ adaptado a la caja de la futura autovía, fueron descubiertas 117 “cubetas", casi todas concentradas en el tramo de la zanja más próximo a la carretera de Abia. En función de los materiales arqueológicos de su relleno, se han podido atribuir con seguridad 1 al Neolítico Antiguo, 11 al Calcolítico Precampaniforme y 16 a la fase Proto Cogotas I del Bronce Medio, siendo clasificadas las restantes como "prehistóricas indeterminadas". En la memoria técnica de los trabajos se califica a los hoyos de "vertederos", salvo en el caso de I-J/88-89 (o cubeta 96) reconocido como "contenedor de una inhumación".

\footnotetext{
${ }^{1}$ Strato S. L. Memoria técnica Excavación arqueológica en el yacimiento de "La Velilla", en Osorno (Palencia), integrada en las obras de la Autovía A-67, de Cantabria a la Meseta. Tramo Osorno-Villaprovedo. [Depositado y disponible en el Servicio Territorial de Cultura de la Junta de Castilla y León de Valladolid]. Inédito 2011.
} 


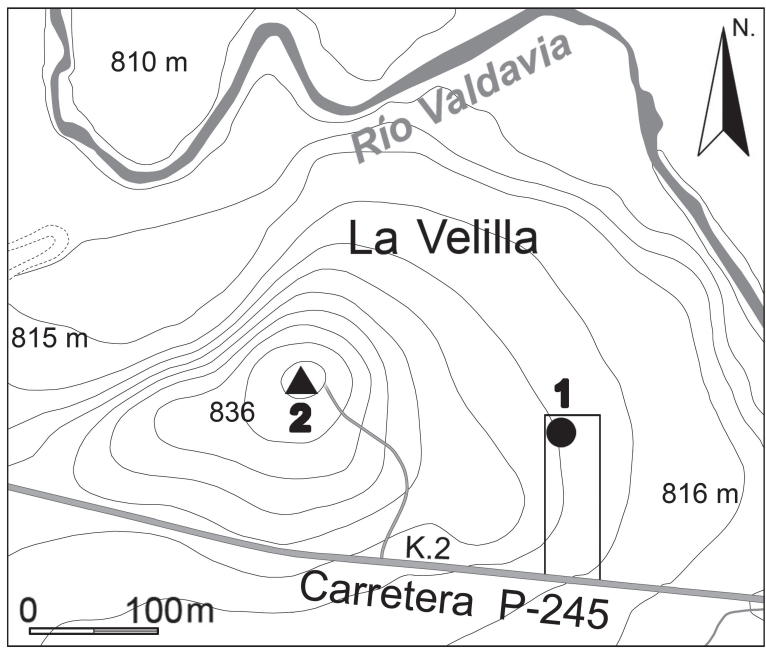

Fig. 2. Localización de la sepultura I-J/88-89: 1. dentro del área de excavación previa a la obra de la autovía en las inmediaciones del dolmen de La Velilla; 2. en Osorno (Palencia). Croquis a partir del Mapa Topográfico Nacional de España 1:25.000 (hoja 198).

\subsection{Descripción y materiales}

El hoyo I-J/88-89, tipológicamente parecido al resto de los excavados, presenta boca circular $(1,2 \mathrm{~m}$ de diámetro) y paredes verticales que tienden a abrirse en el fondo. Ello le confiere cierta forma de botella chata, pues su profundidad relativa, tras el drástico decapado de $40 / 45 \mathrm{~cm}$ al que fue sometido todo el yacimiento, apenas sobrepasa el metro. En el fondo y bien centrada en el hoyo yacía la inhumación, apoyada sobre el costado izquierdo, con las extremidades inferiores flexionadas y contraídas bajo el abdomen, y con los brazos llamativamente separados del cuerpo, sobre todo el izquierdo. La orientación del esqueleto era norte-sur, con el rostro mirando al este.

En la memoria técnica se especifica que el relleno de la fosa, uniforme de techo a suelo, era de tierra cenicienta rica en materia orgánica y en restos de vasijas y de fauna. Y, además, se destacan dos detalles: la aparición de numerosos fragmentos cerámicos junto a la espalda y debajo del esqueleto, y la abundancia de huesos de animales cuya posible condición de ofrendas se discute más adelante (Fig. 3).

\subsection{Los restos humanos}

El esqueleto de I-J/88-89 corresponde a una mujer fallecida entre los 50 y los 60 años, cuyo cadáver fue depositado en el fondo del hoyo en decúbito lateral flexionado, sobre su lado izquierdo. Las piernas

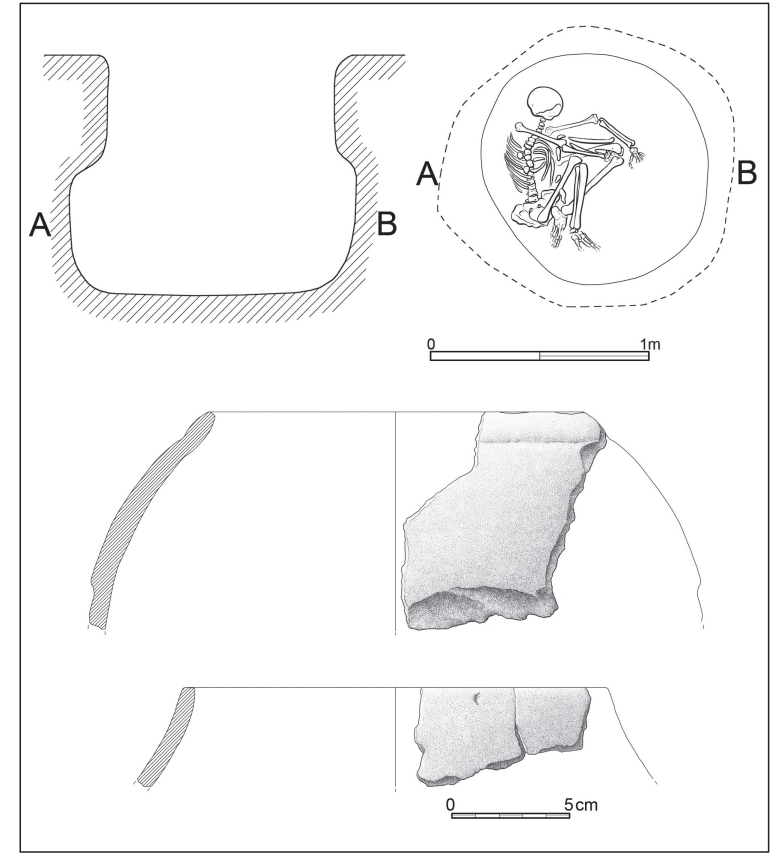

Fig. 3. Tumba I-J/88-89 en hoyo de La Velilla (Osorno, Palencia): planta, sección y muestra de las cerámicas del relleno.

estaban completamente replegadas, algo más la derecha que la izquierda, mientras que los brazos se encontraban estirados y proyectados hacia anterior. La conservación de los huesos es óptima, si bien aquellos en los que domina el tejido esponjoso están más deteriorados y cuentan con un menor grado de representación.

Sin estar del todo claro a qué factores, naturales o antrópicos, se debe la ausencia de algunos de los huesos menores (Fig. 4), sin duda es un depósito primario pues en las fotografías de la excavación se aprecia un mantenimiento general de las conexiones anatómicas, con la excepción de la articulación de los húmeros con sus respectivos cúbito y radio. En el brazo derecho la desvinculación es débil, pero apreciable, en particular en el radio que se desplaza hacia medial; en el izquierdo la separación es más notoria pues cúbito y radio, articulados, se desplazan unos $20 \mathrm{~cm}$ respecto al húmero. Se trata seguramente de movimientos relacionados con la existencia de algún elemento cobertor que retrasara la entrada de sedimento durante el proceso de esqueletización y que permitiera los desajustes descritos (Duday 2009). No se reconocen efectos semejantes en otras partes del esqueleto, tal vez debido a la infrarrepresentación de aquellas regiones esqueléticas en los que podrían ser más evidentes: manos, pies, raquis vertebral y cintura pélvica. 


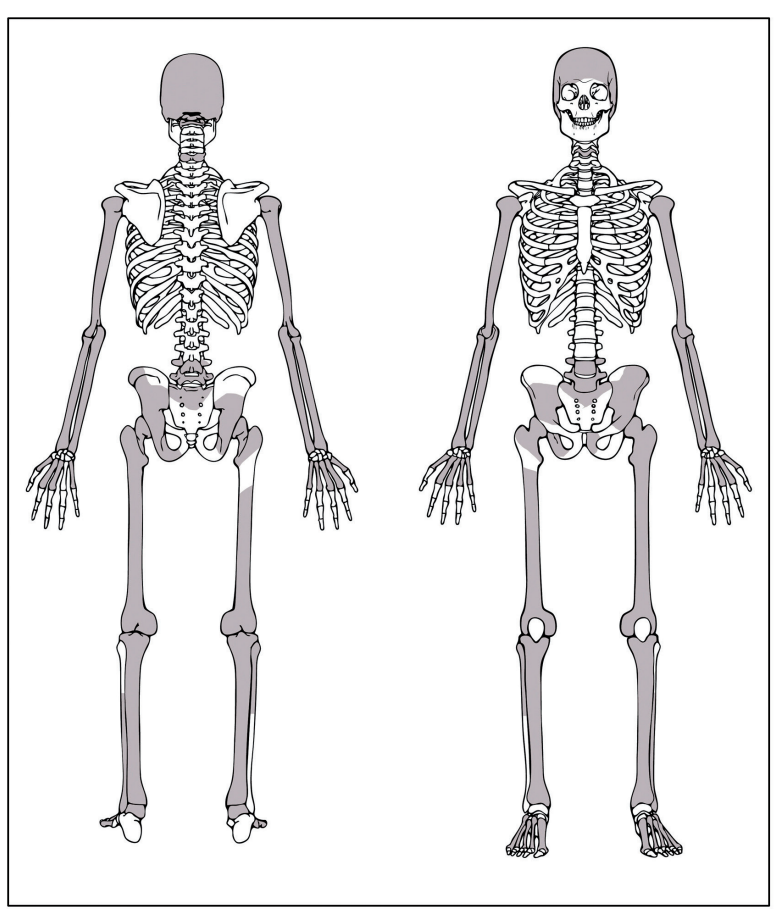

Fig. 4. Esquema de representación del esqueleto de la fosa I-J/88-89 de La Velilla (Osorno, Palencia).

Este grado de representación anatómica parcial no es obstáculo para diagnosticar con precisión, según los protocolos estándares, el sexo del individuo y su edad de muerte. Aquel fue asignado a partir de los rasgos morfológicos del cráneo y de la pelvis (Buikstra y Ubelaker 1994; White y Folkens 2005) y la edad fue estimada mediante la observación de la sínfisis púbica y la faceta auricular (Buikstra y Ubelaker 1994; Buckberry y Chamberlain 2002; Schmitt 2004. De este modo parece firme que los restos corresponden a una mujer fallecida entre los 45 y los 55 años, impresión que confirman otros detalles: los extremos distales de ambos fémures y los proximales de las respectivas tibias, p. ej., evidencian procesos degenerativos en la rodilla, materializados en una ligera modificación de la articulación y en una labiación de sus bordes. Y no faltan nuevas lesiones osteoartrósicas en las lumbares y en las cervicales. También es sintomática la presencia de osteofitos asimétricos en los bordes anteriores de los cuerpos vertebrales, así como una notable porosidad de sus superficies proximales y caudales.

En la extremidad superior se aprecian lesiones parecidas, si bien asimétricas en algunas zonas. Así se detectan signos degenerativos en el extremo distal del húmero derecho (sobre todo labiación de la superficie posterolateral de la tróclea) sin correspondencia en el lado contrario. Con todas las cautelas, bien pudiera ser el resultado de un tipo de actividad en la que el brazo derecho no tuvo el mismo protagonismo que su opuesto. Sin perjuicio de lo dicho, la presencia de un trauma en el radio del mismo lado obliga a ser especialmente reservados al respecto.

Mención aparte merecen las alteraciones constatadas en la región articular de los dos dedos pulgares, consecuencia de procesos degenerativos que se materializan en la presencia de osteofitos (labiación continua) en la región posterior de la articulación distal del primer metacarpo de ambas manos (Mann y Murphy 1990). A priori y debido a su particular manifestación (Fig. 5), la lesión se diría producto de una hiperextensión de tales dedos, muy probablemente en directa asociación a una actividad regular y frecuente que implicara el empleo de cierta fuerza de empuje con la ayuda de las manos. Con todo, valorando la edad del individuo, podría tratarse de un caso de rizoartrosis (artrosis carpometacarpiana), dada su elevada prevalencia en mujeres posmenopáusicas (Burt et al. 2013), lo que, al menos en parte, llevaría a matizar la actividad física como origen de la lesión descrita. La ausencia entre el material recuperado de los carpos y de las respectivas falanges proximales impide ir más lejos en la consideración de la hipótesis.

Pero la patología más singular de este individuo es una fractura de Colles, un traumatismo indirecto localizado en el extremo distal del radio derecho que, en este caso, conllevó un desplazamiento dorsal del frag-

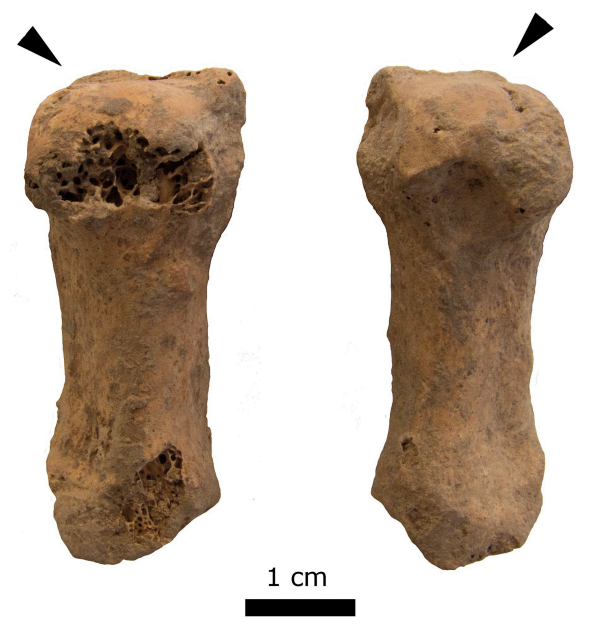

Fig. 5. Vista anterior de los dos metacarpos primeros de la mujer inhumada en La Velilla (Osorno, Palencia). Las flechas señalan los osteofitos localizados en la región posterior de ambos (en color en la edición electrónica). 
A

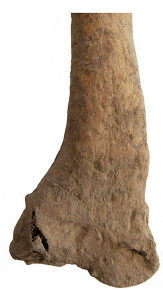

B

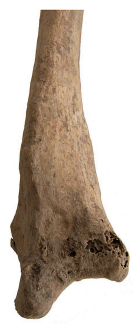

C

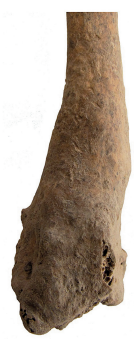

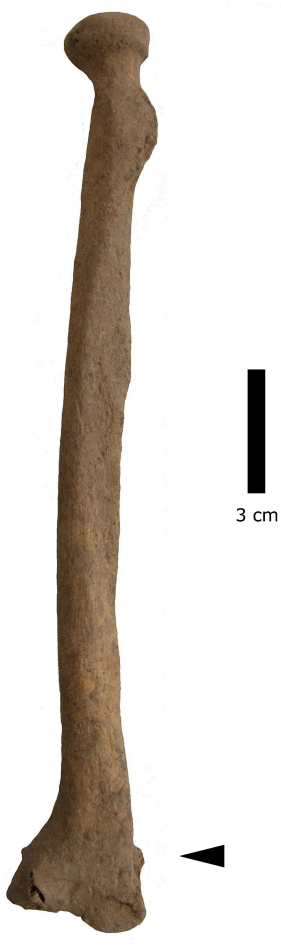

Fig. 6. Radio fracturado en el enterramiento de La Velilla (Osorno, Palencia). Vista: A. anterior; B. medial y C. lateral del extremo distal. La flecha señala el desplazamiento dorsal por fractura de Colles (en color en la edición electrónica). mento distal (Fig. 6). Como norma, se plantea que este tipo de lesiones responde a caídas, al estirar los brazos la víctima para minimizar el impacto con el suelo y absorber el radio casi todo el golpe, lo que ocasiona su rotura (Mays 2006). En nuestro caso, como en la norma, la fractura se produce unos $2 \mathrm{~cm}$ por encima de la superficie articular distal del radio, siendo el desplazamiento resultado directo de la dirección y la fuerza del golpe. Las fracturas de Colles son lesiones traumáticas muy habituales en adultos, muy particularmente en mujeres que han entrado en la menopausia y que sufren procesos osteopénicos severos (Mays 2006; Waldron 2008). Aunque, en rigor, desconozcamos en qué momento de la vida de esta mujer aconteció el trauma, pues el grado de recuperación es completo, dada la casuística comentada y la senectud de la víctima, parece lógico suponer que tuviera lugar a edad avanzada.

Por último, interesan también otros marcadores bioantropológicos, como la presencia de las denominadas fosas de Allen en los cuellos de ambos fémures (Fig. 7). La lesión suele ser de origen biomecánico, asociada al hábito de caminar con regularidad por terrenos escarpados, pero en algún trabajo se considera también su posible carácter congénito. Menos dudas plantea la presencia de fosa septal en los dos húmeros, pues existe amplio consenso sobre su origen epigenético (Mays 2008; Saunders y Rainey 2008). La fosa septal tiene un foramen en la epífisis distal del húmero que conecta las fosas oleocraneana y coronoidea y que, por lo general, y como ejemplifica este caso, suele ser más frecuente en los individuos femeninos que en los masculinos (Mays 2008).

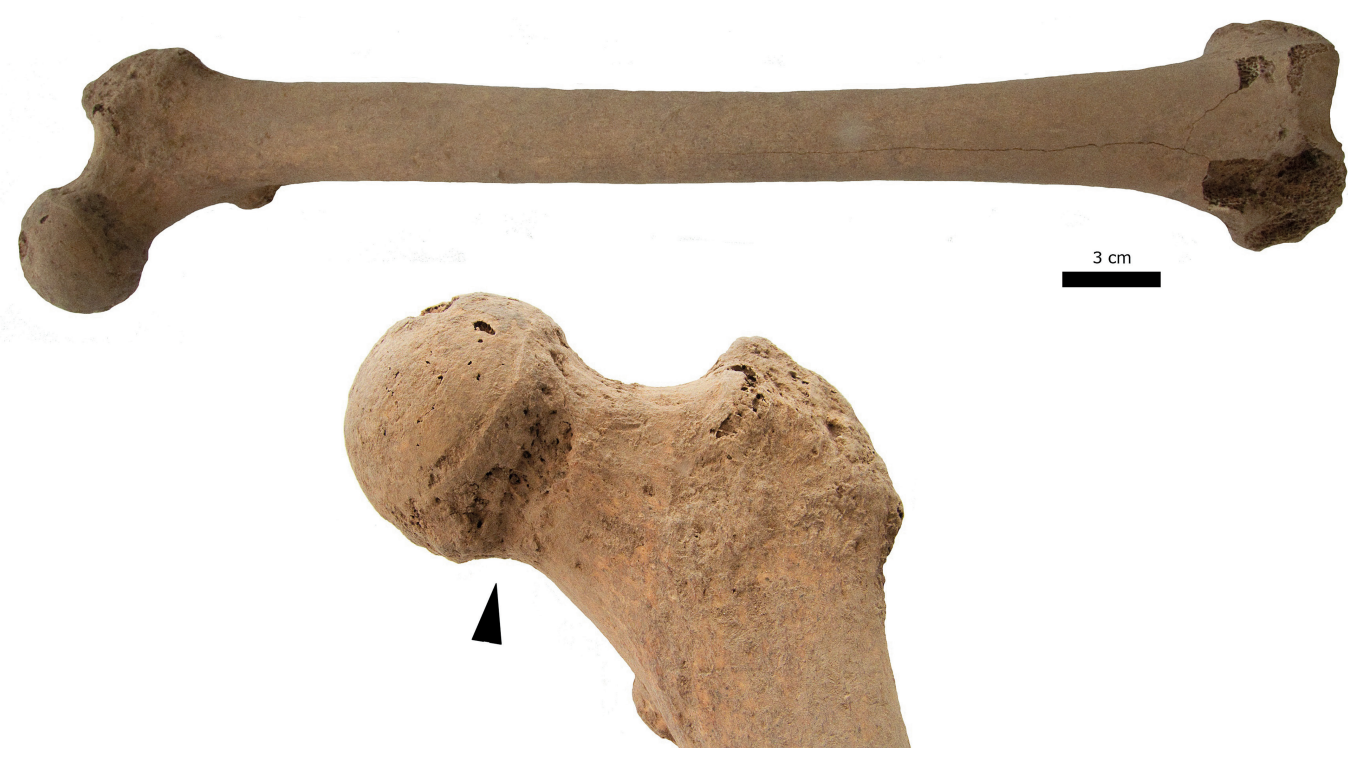

Fig. 7. Fémur izquierdo de la inhumación de La Velilla (Osorno, Palencia). En el detalle inferior se aprecia una lesión de tipo Fosa de Allen (en color en la edición electrónica).

Trab. Prehist., 76, N. ${ }^{\circ}$ 2, julio-diciembre 2019, pp. 236-253, ISSN: 0082-5638

https://doi.org/10.3989/tp.2019.12235 


\subsection{Los restos de macromamíferos del hoyo I-J/88-89}

En el apartado de la memoria técnica dedicado a este hoyo se menciona "una cantidad abundante de restos faunísticos" pero en el Museo Provincial de Palencia apenas se conservan 78 de los cuales solo 65 son identificables. Siempre son huesos de más de $2 \mathrm{~cm}$, prueba de que en la recuperación no medió cribado, y corresponden a fauna doméstica habitual en el Calcolítico de los géneros Bos (4 piezas) y Canis (58), así como de la subfamilia Caprinae (3). Los huesos de vacuno y ovicápridos presentan fracturas antiguas y pertenecen a zonas anatómicas muy distintas por lo que es probable que llegaran a la fosa accidentalmente, junto a las tierras del relleno del hoyo. Los 58 restos de cánido (Anexo 1) se han atribuido a dos ejemplares domésticos (Canis familiaris), uno enterrado completo junto a la inhumación humana, al que corresponden 57 piezas (perro n. $\left.{ }^{\circ} 1\right)$, y el otro (n. $\left.{ }^{\circ} 2\right)$ exclusivamente representado por el cráneo.

\subsection{Datación radiocarbónica}

La muestra utilizada (IHC-1 01) fue un fragmento de peroné, enviado al Laboratorio de Radiocarbono de Poznan donde fue datado mediante técnica AMS con el siguiente resultado: Poz-43074) $4170 \pm 35$ BP (Fig. 8). La calibración a $2 \sigma(95,4 \%$ de probabilidad) con el programa OxCal v.4.3.2 proporciona los estos intervalos: 2885-2831 cal BC (20,3 \%); 2821-2632 cal BC $(75,1 \%)$.

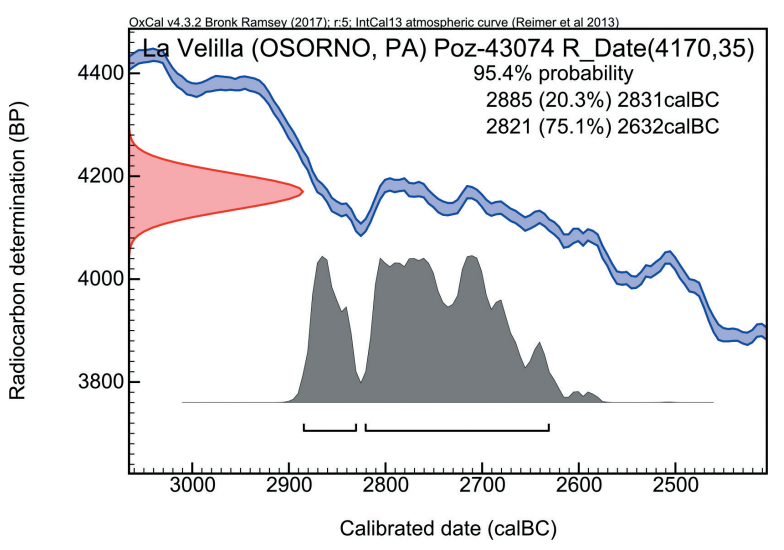

Fig. 8. Datación AMS de los restos humanos de la sepultura de La Velilla (Osorno, Palencia). OxCal v.4.3.2 Bronk Ramsey (2017); r.5; datos atmosféricos a partir de Reimer et al. (2013) (en color en la edición electrónica).

\section{LA FOSA DE CAMINO DE TRASCABAÑAS, EN SIMANCAS (VALLADOLID)}

\subsection{Situación y contexto}

Descubierta en 1985 por J. del Olmo, fue dada a conocer por error como "fosa de Ciguñuela" debido a su cercanía a esta localidad (Delibes 1987); pero el punto en el que se sitúa el yacimiento, a $750 \mathrm{~m}$ s.n.m. y en las coordenadas UTM X: 346.428, Y: 4.608.750 (datum ETRS89 UTM 30N), corresponde inequívocamente al término municipal de Simancas. Fue localizada $-\mathrm{y}$, en gran medida, destruida- al ampliarse el camino de Trascabañas, a unos $30 \mathrm{~m}$ de su intersección con el de Simancas a Ciguñuela, en la margen septentrional de una pequeña cuenca modelada por los arroyos de Santa Marina y de Rodastillo, afluentes del Pisuerga, en cuyo centro se sitúa el dolmen de Los Zumacales (Alonso Díez et al. 2015). Aunque unas suaves lomas impiden la intervisibilidad, a los yacimientos solo les separa un cuarto de hora de marcha (Fig. 9).

\subsection{Descripción y materiales}

Unos meses después del descubrimiento de la fosa, literalmente colgada en el talud del camino, uno de nosotros (GDC) efectuó una pequeña intervención de urgencia. En ella, pese a la desaparición de más de

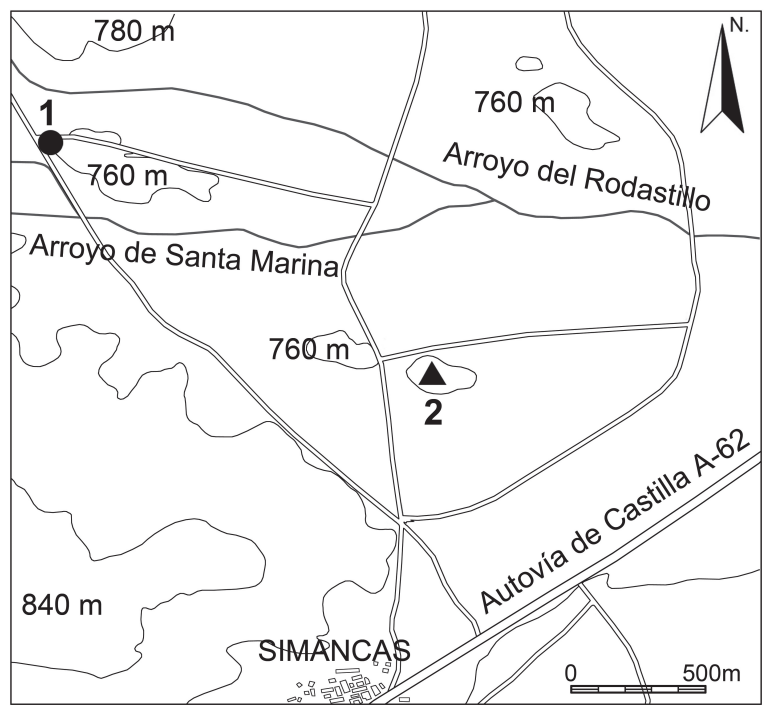

Fig. 9. Localización: 1. sepultura del Camino de Trascabañas; 2. dolmen de Los Zumacales, ambos en término de Simancas (Valladolid). Croquis a partir del Mapa Topográfico Nacional de España 1:25.000 (hoja 372). 

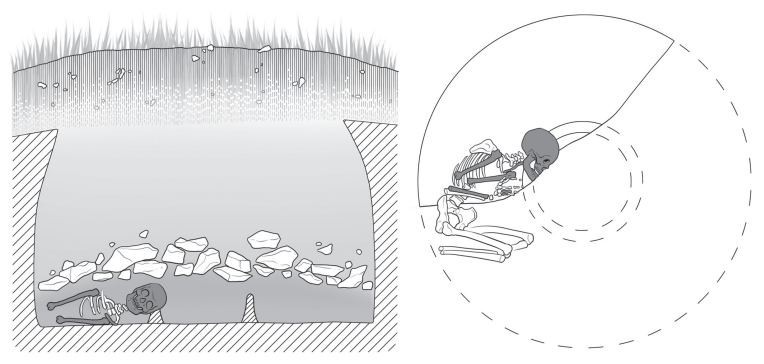
$1 \mathrm{~m}$

Fig. 10. Sección de la tumba del Camino de Trascabañas (Simancas, Valladolid) y propuesta de reconstrucción de la planta del enterramiento. Destacados en oscuro los huesos documentados.

dos tercios del contenedor funerario, todavía pudo reconocerse la forma de un hoyo cilíndrico cuyas paredes tendían a cerrar hacia la boca (Fig. 10), y también apreciarse cómo en su fondo, envueltos en un sedimento carbonoso muy oscuro, se disponían un hogar delimitado por un anillo circular de barro, fuertemente endurecido por el fuego, y huesos humanos en conexión, entre ellos un cráneo que reposaba directamente sobre el anillo. Además, por encima y a modo de protección, existía una capa de bloques calizos y de cantos rodados, y a techo de todo ello un tapón de greda limpia, blanquecina, que alcanzaba hasta la superficie del suelo actual (Fig. 10). Lo mismo en el nivel carbonoso que en el de greda se hallaron restos arqueológicos dispersos - una esquirla de hueso pulimentada, pequeños fragmentos de cerámica, lascas de sílex- que difícilmente, dada su irrelevancia, pueden considerarse elementos de ajuar. Sin embargo, tanto las formas globulares de ciertos vasos como la decoración de uno de ellos - una fina acanaladura horizontal paralela al borde, muy representativa de la alfarería del grupo Las Pozas- permiten asignar la sepultura al Calcolítico Precampaniforme (Delibes 1987).

\subsection{Los restos humanos}

La evidencia antropológica recuperada en el hoyo asciende a poco más de treinta huesos, en general mal conservados debido al recorte del hoyo por la obra del camino pero también a alteraciones previas cuya génesis hay que buscar en los procesos tafonómicos que modificaron el depósito funerario. Los indicios más elocuentes en este sentido son algunas líneas de fractura, el deterioro de parte de los tejidos corticales y, especialmente, la desaparición sistemática de aquellas regiones anatómicas con predominio de hueso esponjoso.

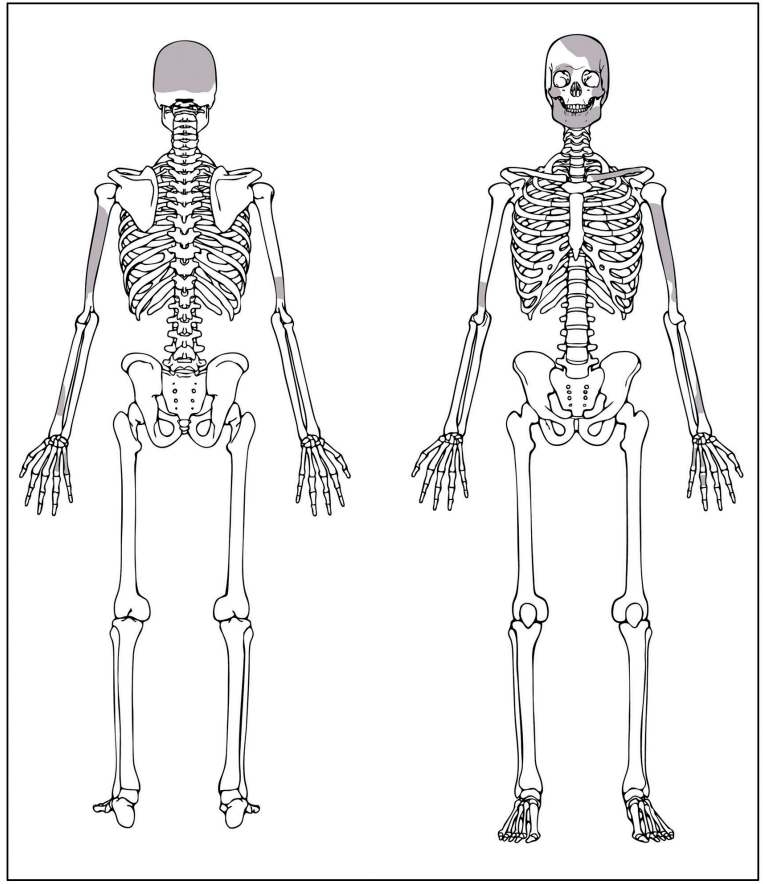

Fig. 11. Esquema de representación del esqueleto de la fosa de Camino de Trascabañas (Simancas, Valladolid).

Aunque la representación anatómica sea muy limitada, la coherencia morfo-anatómica de las evidencias óseas recuperadas se compadece con la idea de que todos los restos pertenecen a una misma persona, y revela que el enterramiento de Trascabañas era individual. Más comprometido, dada la escasez de las pruebas arqueológicas, es dilucidar si era depósito primario o secundario, aunque la diversidad de regiones esqueléticas representadas y la supervivencia de piezas óseas de pequeña entidad (falange, metacarpos...) parezcan más compatibles con la primera idea.

La región anatómica más completa es, con diferencia, el cráneo -frontal, ambos parietales, occipital, así como buena parte de la mandíbula-, seguida de la extremidad superior izquierda, incluida la clavícula de ese lado. En el extremo opuesto, faltan las piezas correspondientes a la cintura pélvica, a la extremidad inferior o al raquis vertebral. En definitiva, el individuo está representado únicamente por parte de los huesos de la mitad superior del esqueleto (el resto habría desaparecido por la destrucción del yacimiento) y, en especial, de su lateral izquierdo, detalle este que responde a que el cadáver se apoyaba precisamente sobre este costado, lo que le sirvió de protección (Fig. 11).

Obviamente, la mencionada subrepresentación anatómica limita el alcance de las valoraciones bioantropológicas relativas a este individuo, pero no impide

Trab. Prehist., 76, N. . 2, julio-diciembre 2019, pp. 236-253, ISSN: 0082-5638

https://doi.org/10.3989/tp.2019.12235 
ciertas consideraciones sobre su condición sexual y edad de muerte. Las características morfológicas del cráneo (los fragmentos conservados de la región frontal, proceso mastoideo, occipital y mandíbula) manifestarían su probable carácter femenino, lo mismo que el tamaño y la gracilidad de los pocos huesos recuperados del esqueleto postcraneal.

Además, el desgaste de las superficies oclusales de los molares apunta a una muerte entre los 30 y los 45 años (Buikstra y Ubelaker 1994), edad de muerte que se confirma ponderando el desgaste de las superficies oclusales de las piezas dentales delanteras. Y, complementariamente, el grado de exposición de la dentina secundaria en los primeros y segundos molares de la mandíbula, aparte de indicar la ingesta habitual de productos abrasivos con la dieta, denota también el fallecimiento con toda probabilidad entre los primeros 40 y los 55 años (Buikstra y Ubelaker 1994). Finalmente, no se advierten lesiones ni alteraciones óseas significativas, aunque la apreciación solo sea aproximativa dada la parcialidad y precario estado de conservación de la muestra.

\subsection{Análisis genético}

En el contexto de la tesis doctoral de Palomo-Díez (2015) se llevó a cabo el análisis genético de las Regiones Hipervariables I y II del ADN mitocondrial del individuo de Trascabañas. Tras diversas amplificaciones de cada región, y cumpliendo con los principales criterios de autenticidad del ADN crítico (Pääbo et al. 2004) se obtuvo el siguiente haplotipo consenso: 73G, 150T, 263G, 315.1C, 338T. Una vez determinado el haplotipo, se trató de asignar el haplogrupo mediante la búsqueda en tres bases de datos de ADN mitocondrial (EMPOP, mtDNA Manager y Ibermitobase) y utilizando la herramienta Haplogrep. Así, según $\mathrm{Ha}$ plogrep, el haplogrupo más probable del individuo sería el U5b2a1a2; según $E M P O P$, el más probable sería el H4a1a1a1; respecto a Ibermitobase, también lo ubicó en los haplogrupos U3 o U5b; y por su parte $m t D N A$ Manager no consiguió asignar ningún haplogrupo.

Ante esta diversidad de resultados, se llevó a cabo un segundo análisis genético, profundizando en el estudio de la porción codificante del ADN mitocondrial, concretamente en la posición 12308 , que permitiría descartar o confirmar la pertenencia a la rama U. De este modo, se hallaron los polimorfismos 12308A y 12312C. Esto descartaría la pertenencia a cualquier haplogrupo de la rama $U$, dado que para ello en la posición 12308 debería haber una guanina $(\mathrm{G})$ en lugar de una adenina (A). Adviértase que el haplotipo mitocondrial del individuo de Trascabañas es muy poco frecuente en la población actual, probablemente debido a las mutaciones $338 \mathrm{~T}$ y $12312 \mathrm{C}$, que podrían ser específicas del linaje de este individuo (mutación "privada").

Dentro de la base de datos EMPOP, el individuo presenta mayor probabilidad de pertenecer al haplogrupo H4a1ala1, basándose en la mutación $73 \mathrm{G}$, que es diagnóstica de este subhaplogrupo concreto, en combinación con el resto de las mutaciones halladas.

Con estos datos, cabrían dos posibilidades: a) que el individuo pertenezca al haplogrupo H4alala1, tal como estima EMPOP; b) que el linaje mitocondrial del individuo presente una mutación privada en la posición 12308, ubicándose realmente en la rama U, y con mayor probabilidad a los haplogrupos U5b o U3, tal como apuntan la aplicación Haplogrep y la base de datos Ibermitobase.

El macrohaplogrupo $\mathrm{H}$ es típicamente europeo; sin embargo, su rama $\mathrm{H} 4$ presenta una distribución irregular, no muy común en Centroeuropa (Pereira et al. 2005), localizándose su máxima frecuencia en la población actual de la península ibérica y especialmente en la mitad norte (según $E M P O P$, https://empop.online). Según Brotherton et al. (2013) se ha detectado varias veces la coexistencia de este subhaplogrupo $\mathrm{H} 4$ con poblaciones extrapeninsulares asociadas al Vaso Campaniforme y la Cerámica Cordada, pudiendo haberse diversificado (al igual que los H3, H2a, H7 y H11) de forma paralela a la expansión de estas culturas.

Pero si la posición 12308 presentara una mutación puntual ("privada") dentro del linaje de este individuo, el mismo podría ubicarse dentro de la rama $\mathrm{U}$, y con mayor probabilidad en sus vertientes U5b o U3.

La rama U5b en la actualidad es un haplogrupo que muestra una elevada presencia en la Región Franco-Cantábrica de la península ibérica (Cardoso et al. 2011). Además, el haplogrupo U5b es relativamente frecuente en la península a partir del Mesolítico, cuando se ha detectado por primera vez en esta región, concretamente en La Braña-Arintero (León) (SánchezQuinto et al. 2012) y en Aizpea (Navarra) (Hervella et al. 2012). Después, se ha reiterado la presencia del haplogrupo U5b, desde el Mesolítico hasta el Bronce Tardío (Núñez et al. 2016; Martiniano et al. 2017; Szécsényi-Nagy et al. 2017). En cambio, el haplogrupo U3 es mucho menos frecuente que el U5b (Szécsényi-Nagy et al. 2017).

Para concluir: aunque el haplogrupo U5b está presente a lo largo de estos periodos, el $\mathrm{H}$ sigue siendo el mayoritario (Núñez et al. 2016; Martiniano et al. 2017; Szécsényi-Nagy et al. 2017); en cambio, en ninguno de estos trabajos se ha detectado la presencia del subhaplogrupo $\mathrm{H} 4$, lo cual indica su baja prevalencia a lo largo de los periodos estudiados, siendo más frecuentes las ramas H1 y H3 (Núñez et al. 2016). 
Para la determinación genética del sexo del individuo también se estudió un fragmento del gen de la amelogenina mediante Real Time PCR, realizándose cuatro amplificaciones independientes de dicho marcador (dos y dos, a partir de muestras distintas) que permitieron diagnosticar el sexo molecular del individuo como varón. Con arreglo al protocolo, se consideró válido el resultado del sexo molecular tras replicarlo en los 4 análisis independientes.

\subsection{Datación radiocarbónica}

La muestra (GGN 01), con contenido en colágeno $1,5 \% \mathrm{~N}$ y $6,7 \% \mathrm{C}$, fue un fragmento distal de la diáfisis del húmero derecho. Fue datada mediante técnica AMS en el Laboratorio de Radiocarbono de Poznan, arrojando el siguiente resultado: Poz-31722: $4180 \pm 35$ BP (Fig. 12). Su calibración con el programa OxCal v.4.3.2 proporciona, a $2 \sigma(95,4 \%$ de probabilidad), los intervalos $2889-2833$ cal BC (21,9\%); 2819-2661 cal BC (71,4 \%); 2649-2665 cal BC (2,1\%).

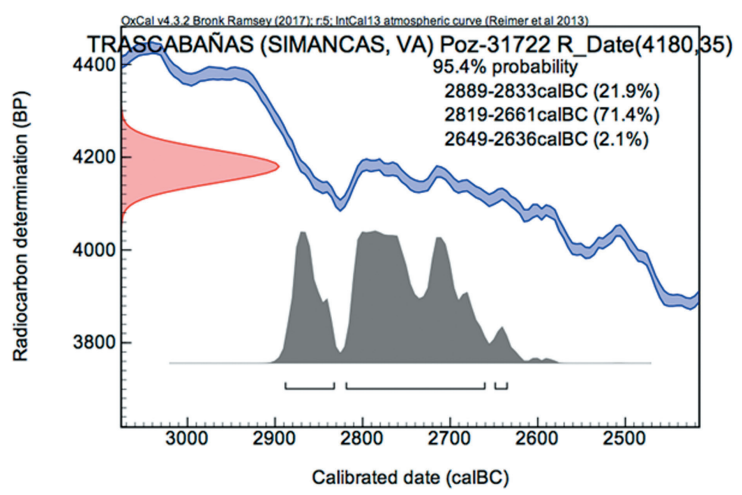

Fig. 12. Datación AMS de los restos humanos de la sepultura del Camino de Trascabañas (Simancas, Valladolid). OxCal v.4.3.2 Bronk Ramsey (2017); r.5; datos atmosféricos a partir de Reimer et al. (2013) (en color en la edición electrónica).

\section{DISCUSIÓN}

\subsection{Norma funeraria y aspectos bioantropológicos}

Su estudio ha progresado en los últimos años, a raíz de descubrirse numerosas sepulturas a uno y otro lado del Sistema Central, pero la gestión de la muerte entre las comunidades calcolíticas precampaniformes de la meseta sigue siendo un tema mal conocido, revelándose excesivamente reduccionista la idea inicial de que frente a los osarios colectivos de los viejos dólmenes se impuso un modelo de tumba individual, en fosa, que introducía la doble novedad de anteponer los valores personales a los comunitarios y de ocultar la muerte (Esparza et al. 2008: 32; Delibes 2014: 107).

Una de las razones es que el número de sepulturas conocidas es demasiado bajo para no sospechar que los enterramientos depositados en ellas solo representan la excepción de una norma que la arqueología aún no ha logrado descifrar. Algunos investigadores, atendiendo al hecho de que no pocas de las fosas acogen enterramientos parciales e inhumaciones en fase de momificación y advirtiendo asimismo el acusado aislamiento de tales tumbas, que jamás se agrupan en necrópolis, se preguntan si el primer destino del grueso de la población fallecida no habría sido un gran osario similar a los documentados en otras zonas peninsulares, caso de los hipogeicos de San Juan ante Portam Latinam y Camino del Molino (Fabián y Blanco 2012: 115). Y otros, más eclécticamente, se limitan a recordar que los muertos de las fosas no constituyen en determinadas zonas, como el NE de la meseta, sino una fracción de los fallecidos, por haberse buscado acomodo a los restantes en cuevas convertidas en panteones (Atapuerca), en antiguos dólmenes todavía activos (Arroyal I), en fosas colectivas alejadas de los hábitats (Los Cardos) o bajo túmulos de nueva planta, como el de Cótar (Carmona et al. 2013: 74). La confirmación de la primera de tales hipótesis, extrapolable en líneas generales a los enterramientos de los "campos de hoyos" de la Edad del Bronce de la propia meseta, una vez demostrado que antes de llegar a las fosas muchos de los muertos Cogotas I pasaban tiempo en un expositor o pudridero (Esparza et al. 2012), sigue a la espera del descubrimiento de un gran contenedor de cadáveres primarios, pues la fosa colectiva abulense de El Tomillar, con sus once esqueletos, o la burgalesa de Los Cardos, bastante mayor, son depósitos de enterramientos trasladados o secundarios (Fabián 1995: 147; Arnáiz et al. 1997). La explicación de Carmona, en principio aplicable a la cuenca del Arlanzón, no lo es tanto para el valle medio del Duero donde ni se conocen osarios en cueva, ni hay constancia de que se levantaran nuevos túmulos, ni los pocos megalitos documentados, como veremos, continuaban operativos en los inicios de la Edad del Cobre.

Pero la representatividad de la muestra no es el único problema relativo al tema de la muerte durante el Calcolítico meseteño. Otro es la falta de una explicación general de por qué, frente a una mayoría de sepulturas individuales, existen otras múltiples, con varios individuos enterrados conjuntamente. La fosa n. ${ }^{\circ} 1$ del Cerro de la Cabeza (Ávila), que contenía los cuerpos de seis personas asaeteadas, seguramente represente una solución de emergencia (el resto de las inhumaciones del yacimiento son individuales), que se

Trab. Prehist., 76, N. ${ }^{\circ} 2$, julio-diciembre 2019, pp. 236-253, ISSN: 0082-5638

https://doi.org/10.3989/tp.2019.12235 
adoptó, atendiendo a razones económicas y simbólicas (yacija común para los fallecidos en común empeño), para gestionar las consecuencias de un episodio bélico (Fabián y Blanco 2012: 113). Pero no deja de ser una circunstancia excepcional, no extrapolable al conjunto de las tumbas múltiples de esta época (Aliaga 2008: 26: Gómez et al. 2011: 118; Fabián y Blanco 2012: 116), ni fácil de compaginar con la impresión de los investigadores de Camino de Las Yeseras de que mientras las sepulturas individuales corresponden exclusivamente a adultos, las colectivas se reservaban a la población infantil (Liesau et al. 2008: 109).

Más, inclusive haciendo abstracción de estas tumbas múltiples que, como decimos, podrían no ser normativas, tampoco entre las inhumaciones simples se dan las regularidades necesarias para deducir la existencia de un patrón funerario definido. Porque una mayoría de tales sepulturas son primarias, pero las hay también con signos de haber sido realizadas en dos tiempos; porque se registran tanto inhumaciones completas como parciales; porque mientras los cuerpos de los difuntos aparecen cuidadosamente dispuestos en el fondo de algunos hoyos, en otros se diría que han sido despectivamente tirados, sin la menor solemnidad; porque ni siquiera entre los primeros se registran posturas y orientaciones tipificadas; porque, dada la escasez de ofrendas, resta aún por saber hasta qué punto era costumbre o no realizarlas, etc (Fabián 1995; Díaz del Río et al. 1997: 103-105; Aliaga 2008; Esparza et al. 2008; Carmona et al. 2013). Entendiendo que muchos de tales interrogantes tienen su origen en la cortedad de la muestra documental disponible, nos detenemos a comprobar en qué medida las nuevas tumbas individuales de La Velilla y Trascabañas contribuyen a despejarlos:

a. La posición aislada de ambos hallazgos refuerza la idea de que las tumbas no se agrupan en cementerios o áreas sepulcrales. En Trascabañas la documentación sobre el entorno es menos contundente, pero I-J/88-89 es el único hoyo funerario de los 11 calcolíticos constatados en La Velilla, no registrándose ningún otro en la casi media hectárea $\left(4800 \mathrm{~m}^{2}\right)$ excavada. Desconocemos si los 10 hoyos restantes contienen restos de actividades ceremoniales o si -como ocurre en otros yacimientos (Carmona et al. 2013: 55)- son simples silos en espacios específicos de almacenamiento de productos subsistenciales; pero sea cual sea la situación, nuestros documentos insisten en la idea de la "muerte ubicua" defendida por Márquez (2004).

b. Los nuevos hallazgos en nada modifican la imagen de escasez de enterramientos infantiles, pues los dos esqueletos son de adultos, pero sí es interesante que uno sea de una mujer ya que corrige en parte la severa desproporción habida hasta ahora a favor de las tumbas masculinas (Tab. 1). La mujer de La Velilla, de edad avanzada o muy avanzada (45-55), supera claramente la media de vida considerada para la población femenina de este periodo (Carmona et al. 2013: 72). Ello se compadece con las lesiones degenerativas propias del envejecimiento advertidas en su esqueleto: problemas artrósicos en rodillas, en vértebras lumbares y cervicales y en los pulgares de ambas manos, así como una factura de Colles en el radio derecho (con toda probabilidad ocasionada por una caída) pues es lesión común en mujeres mayores afectadas por procesos de osteopenia. Por último, también se observan patologías vinculables a estrés ocupacional: por un lado, degeneración del extremo distal del húmero derecho, sin correspondencia en el brazo opuesto, fácilmente relacionada con una actividad que exigió utilizar de forma prolongada y recurrente el brazo de ese lado; deformaciones también en los pulgares, producidas, al menos en parte, por hiperextensión de los dedos; y, además, presencia de fosas de Allen en los cuellos de ambos fémures, cuyo origen puede asociarse, entre otros, a caminar por zonas escarpadas (Capasso et al. 1999). Unos datos, en fin, de indudable interés aunque solo en parte novedosos dentro del panorama bioantropológico del Cobre meseteño (Fabián 1995; Gómez et al. 2011: 126-130; Fabián y Blanco 2012; Carmona et al. 2013: 73).

c. Aunque en Trascabañas solo se recuperara el extremo superior del esqueleto, debido al arrasamiento de casi toda la fosa, y pese al poco cuidadoso levantamiento del cadáver en La Velilla, parece claro que son enterramientos primarios, a distinguir de otros -Cerro de la Cabeza 3, p. ej. (Fabián y Blanco 2012: 109)- con solo parte de los huesos y desorganizados. Repiten en este sentido la fórmula más común de las inhumaciones individuales calcolíticas y los dos (seguro en La Velilla, muy probable en Trascabañas) adoptan la postura de decúbito lateral flexionado, reveladora de que los cuerpos ya habían perdido el rigor mortis cuando se introdujeron en el hoyo. No es menos interesante reparar además en que ambos esqueletos, pese a corresponder a individuos de diferente género, se apoyan sobre el costado izquierdo, prueba de que, como se sospechaba (Esparza et al. 2008: 33), el ritual no discriminaba posturas en función del sexo.

d. Al situarse las inhumaciones de Osorno y Simancas en el fondo de los hoyos se deduce que estos fueron excavados ex profeso, no como otros - p. ej. la fosa 103 de El Hornazo, en Burgos (Carmona et al. 2013: 57) o la mayoría de las de Las Matillas, Madrid (Díaz del Río et al. 1997: 105) — cuya utilización funeraria se materializó cuando ya se hallaban medio rellenos de detritus. Sin embargo, en ambos casos el depósito del cadáver solo se produjo después de cierto acondicionamiento de la fosa, porque el esqueleto de Trascabañas reposaba directamente sobre un hogar 
anular de barro lleno de brasas y el de La Velilla sobre un lecho o tapiz de trozos de cerámica, especialmente tupido a espaldas de la inhumada.

Las huellas de fuego en sepulturas neolíticas y de la Edad del Cobre son frecuentes y, aunque no siempre esté claro a qué gestos responden (Zammit 1991; Fernández Crespo 2016), sí parece evidente su condición ceremonial en una sepultura calcolítica múltiple de la cueva del Portalón, en Atapuerca, donde en el piso sobre el que descansaban los muertos, también revestido de cerámicas, se disponían varios hogares perfectamente circulares asociados a huesos de cordero (Pérez Romero et al. 2017). Y respecto a la abundancia de cerámicas en la fosa de La Velilla, una explicación habitual ante hallazgos similares es que se trata de las vasijas procedentes de festejos relacionados con la despedida del difunto (Carmona 2011: 504-505; Fabián y Blanco 2012: 104), unas ceremonias formalmente similares a las celebradas en otros campos de hoyos para reforzar los valores comunitarios (Díaz del Río 2001: 249-250; Blanco González 2014). Sin embargo, la disposición de los fragmentos formando un pavi- mento opera en contra de la interpretación comensal, pues en el registro de la mencionada sepultura de la cueva del Portalón de Atapuerca queda bien claro que una cosa son los añicos de cerámica que tapizan el suelo y otra las vasijas más o menos completas depositadas como ofrendas o utilizadas en la libación (Pérez Romero et al. 2017).

e. En Trascabañas la parte superior del cadáver, única conservada, aparecía ostensiblemente lastrada por piedras, hecho que se repite en no pocas fosas calcolíticas: 2 y 4 del Cerro de la Cabeza (Fabián y Blanco 2012: 107 y 110), Soto de Tovilla (Esparza et al. 2008: 16), Colmenares (Herrán y Rojo 1999: 111), etc. El primer pensamiento al respecto es que se trataba de una protección para obstaculizar la profanación de la sepultura y, en consecuencia, que los enterradores concebían las fosas como "tumbas cerradas" -y seguramente no señalizadas- en las que los muertos, encapsulados, quedaban aislados para siempre del mundo de los vivos (Barrett 1988; Thomas 1991: 118; Bradley 1998: 49). Sin embargo este presumible empeño de ocultar y dejar definitivamente atrás la muerte, tan ale-

\begin{tabular}{|c|c|c|c|c|c|c|c|}
\hline & Postura & Primaria & Sexo & Edad & $\begin{array}{c}\text { Ofrendas/ } \\
\text { Ajuares }\end{array}$ & Reliquias & Datación \\
\hline $\begin{array}{l}\text { Cerro de la Cabeza } 2 \\
\text { (Ávila, AV) }\end{array}$ & $\begin{array}{c}\text { DSO } \\
\text { Descuidada }\end{array}$ & ¿Si? & Varón & $40-45$ & & $\mathrm{Si}$ & $\begin{array}{l}\text { Beta 109828: } 4010 \pm 50 \\
\text { Fabián y Blanco } 2012\end{array}$ \\
\hline $\begin{array}{l}\text { Cerro de la Cabeza } 3 \\
\text { (Ávila, AV) }\end{array}$ & Descuidada & No & Varón & $15-16$ & $\begin{array}{l}\text { ¿diente de } \\
\text { hoz? }\end{array}$ & No & $\begin{array}{c}\text { Beta 109829: } 3820 \pm 60 \\
\text { Fabián y Blanco } 2012\end{array}$ \\
\hline $\begin{array}{l}\text { Cerro de la Cabeza } 4 \\
\text { (Ávila, AV) }\end{array}$ & $\begin{array}{c}\text { DLI } \\
\text { Flexionada }\end{array}$ & No & Varón & $40-50$ & perro & $\mathrm{Si}$ & $\begin{array}{l}\text { Beta 109831: } 3850 \pm 60 \\
\text { Fabián y Blanco } 2012\end{array}$ \\
\hline $\begin{array}{l}\text { Fuente Celada } 19 \\
\text { (Quintanadueñas, BU) }\end{array}$ & $\begin{array}{c}\text { DP } \\
\text { Descuidada }\end{array}$ & $\mathrm{Si}$ & Mujer & $19-22$ & & & \\
\hline $\begin{array}{l}\text { Fuente Celada 62 } \\
\text { (Quintanadueñas, BU) }\end{array}$ & $\begin{array}{c}\text { DLI } \\
\text { Flexionada }\end{array}$ & $\mathrm{Si}$ & Varón & ¿50? & $\begin{array}{l}\text { tres aros de } \\
\text { hueso }\end{array}$ & & \\
\hline $\begin{array}{l}\text { El Hornazo } 103 \\
\text { (Villímar, BU) }\end{array}$ & $i ?$ & ¿? & Alofiso & $13-14$ & vasija & No & $\begin{array}{c}\text { UGA- 6838: } 4010 \pm 25 \\
\text { Carmona et al. } 2013\end{array}$ \\
\hline $\begin{array}{l}\text { EI Hornazo } 140 \\
\text { (Villímar, BU) }\end{array}$ & $\begin{array}{c}\text { DLI } \\
\text { Flexionada }\end{array}$ & $\mathrm{Si}$ & Alofiso & $17-18$ & ¿cuenta collar? & $\mathrm{Si}$ & $\begin{array}{c}\text { UGA- 6995: } 4100 \pm 25 \\
\text { Carmona et al. } 2013\end{array}$ \\
\hline $\begin{array}{l}\text { La Velilla } \\
\text { (Osorno, PA) }\end{array}$ & $\begin{array}{c}\text { DLI } \\
\text { Flexionada }\end{array}$ & $\mathrm{Si}$ & Mujer & $45-55$ & perro & No & Poz 42074: $4170 \pm 37$ \\
\hline $\begin{array}{l}\text { Colmenares } \\
\text { (Portillo, VA) }\end{array}$ & ¿? & ¿Si? & Mujer & $19-?$ & $\begin{array}{c}\text { vasija y } \\
\text { punzón de } \\
\text { cobre }\end{array}$ & $\mathrm{Si}$ & \\
\hline $\begin{array}{l}\begin{array}{l}\text { Soto Tovilla } \\
\text { (Tudela, VA) }\end{array} \\
\end{array}$ & $\begin{array}{c}\text { DLI } \\
\text { Flexionada } \\
\end{array}$ & $\mathrm{Si}$ & Varón & $20-25$ & vasija & No & $\begin{array}{c}\text { Poz 25974: } 4065 \pm 35 \\
\text { Esparza et al. } 2008 \\
\end{array}$ \\
\hline $\begin{array}{l}\text { Trascabañas } \\
\text { (Simancas, VA) }\end{array}$ & $\begin{array}{c}\text { DLI } \\
\text { Flexionada }\end{array}$ & $\mathrm{Si}$ & Varón & $30-45$ & & No & Poz 31722: $4180 \pm 35$ \\
\hline
\end{tabular}

Tab. 1. Cuadro resumen de posturas, sexo, edad, ofrendas y cronología de los principales enterramientos individuales en fosa del Cobre Precampaniforme de la cuenca del Duero. AV Ávila, BU Burgos, PA Palencia, VA Valladolid; DLD Decúbito lateral derecho, DLI Decúbito lateral izquierdo, DP Decúbito prono, DSO Decúbito supino.

Trab. Prehist., 76, N.. 2, julio-diciembre 2019, pp. 236-253, ISSN: 0082-5638

https://doi.org/10.3989/tp.2019.12235 
jado por otra parte de la idea tradicional de que enterrar a los difuntos es sobre todo una forma de perpetuar su memoria y de honrarlos como antepasados, no se corresponde por completo con la realidad de los hechos: La posición de una de las fosas de inhumación de Camino de Las Yeseras, p. ej., obligó a desviar el trazado de uno de los fosos, prueba de que disponía de algún tipo de señalización externa (Liesau et al. 2008: 110); y, sobre todo, está plenamente demostrado que inclusive sepulturas con lastre de piedras fueron reabiertas, p. ej. Cerro de la Cabeza 4 cuyo esqueleto sufrió el espolio del húmero derecho y de parte de la mandíbula (Fabián y Blanco 2012: 110). Todos estos detalles, unidos a la habitual presencia en las tumbas de huesos humanos sueltos que, subrayamos, no corresponden al individuo inhumado (Herrán y Rojo 1999: 118; Aliaga 2008: 33; Fabián y Blanco 2012: 116), sino que han sido incorporados desde otras sepulturas o depósitos, revela que la supuesta estanqueidad de aquellas es muy relativa y que tanto la circulación de reliquias como el culto a los antepasados estuvieron más presentes de lo que habitualmente -por oposición al mundo dolménico- se considera entre las poblaciones del Calcolítico meseteñas (Esparza et al. 2008: 31; Carmona et al. 2013: 74).

\subsection{La dimensión simbólica de la ofrenda de perros}

Ya anticipamos que en el hoyo I-J/88-89 de La Velilla aparecieron restos de dos perros y unos pocos huesos de vacuno y caprino cuya posición exacta respecto a la inhumación se desconoce. Los últimos, a juzgar por su escasez, por su acusado rodamiento, por las fracturas antiguas que presentan y por corresponder a partes anatómicas inconexas, debieron de incorporarse accidentalmente al relleno del hoyo tras permanecer algún tiempo en superficie (un calcáneo de Bos presenta mordeduras de carnívoro). Sin embargo, en el caso del perro n. ${ }^{\circ} 1$, cuyo esqueleto se conserva prácticamente entero, parece tratarse del depósito de un ejemplar completo. Menos claras resultan, como veremos, las circunstancias en que accedió a la fosa el cráneo aislado del perro n. ${ }^{\circ} 2$.

La introducción de cadáveres de perro en tumbas, de animales presumiblemente inmolados para escoltar a sus propietarios, es costumbre que en el Viejo Mundo se remonta al Mesolítico y tal vez, inclusive, a finales del Paleolítico Superior a juzgar por el documento de Bonn-Oberkassel (Davis y Valla 1978; Morey 2010: 24-25). En el mediodía de la península ibérica, donde no se conocen testimonios comparables hasta bien avanzado el Neolítico (Lizcano et al. 1992), la práctica alcanzó su culmen en la Edad del Cobre cual ilustra el medio centenar de personas enterradas en compañía de sus respectivos canes en el sepulcro colectivo de Camino del Molino, Murcia (Lomba et al. 2009). Y también en las tierras de la meseta, tanto durante el Calcolítico -tumbas de El Cerro de la Cabeza (Ávila), Los Cercados (Valladolid) o el entorno de Madrid- como en la Edad del Bronce está acreditada la existencia de costumbres similares por más que la cifra de los perros que acabaron convirtiéndose en ofrendas funerarias o en acompañamiento de cadáveres sea por el momento inferior a la de los involucrados en otros rituales de signo diferente (Liesau et al. 2014: 109).

Los canes enterrados junto a sus dueños es lógico pensar que fueran sacrificados para la ocasión, lo que hasta cierto punto se compadece con el predominio de ejemplares adultos jóvenes en Camino del Molino y con el patrón de mortalidad (12-24 meses) registrado entre los animales de Yeseras (Daza Perea 2011: 2018). También el perro n. ${ }^{\circ} 1$ de La Velilla, un macho adulto del que se conserva el báculo peneano, murió joven, entre los 3 y los 4 años a juzgar por el desgaste de las carniceras inferiores. Sin embargo, pese a su completo registro esquelético, no se conservan en los huesos huellas reveladoras de cómo se produjo su sacrificio, aunque pudieran guardar relación con él las fracturas limpias producidas perimortem en las zonas medias de tres de los huesos largos de las extremidades delanteras: ambos radios y el húmero izquierdo (Fig. 13).

Las características morfológicas del cánido que nos ocupa remiten a un perro de talla media (mesomorfo) y de huesos más bien gráciles, en principio adecuado para todo tipo de actividad (caza, pastoreo, guarda), pero una ostensible artropatía en una de las vértebras torácicas debió de limitar sus movimientos. La lesión, una espondiloartrosis responsable de un recrecimiento óseo en el entorno de la articulación distal de la vértebra, dañando los discos, es propia de animales adultos, como nuestro ejemplar, y no parece especialmente relacionada con sobreesfuerzos físicos derivados de actividad de carga como los registrados en otros perros prehistóricos peninsulares (Albizuri et al. 2011; Liesau et al. 2014). Su alzada en la cruz, que llegaba a los $56 \mathrm{~cm}$ de acuerdo con los índices para los huesos largos de Koudelka (1885) y Harcourt (1974), está claramente por encima de la de un ejemplar coetáneo de Yeseras, establecida en $45 \mathrm{~cm}$ (Daza Perea 2011: 218) y de la mayoría de los perros clasificados como "cánidos de tamaño medio" del Camino de la Cruz (Ruíz García-Vaso et al. 2013). También supera a la de los perros de la Edad del Bronce de la meseta - Camino de Yeseras (Daza Perea 2011) o La Huelga, en Dueñas (Liesau et al. 2014) - , cuya altura rara vez excede el medio metro. Sin embargo, sus características tanto morfológicas como biométricas, en especial las cra- 

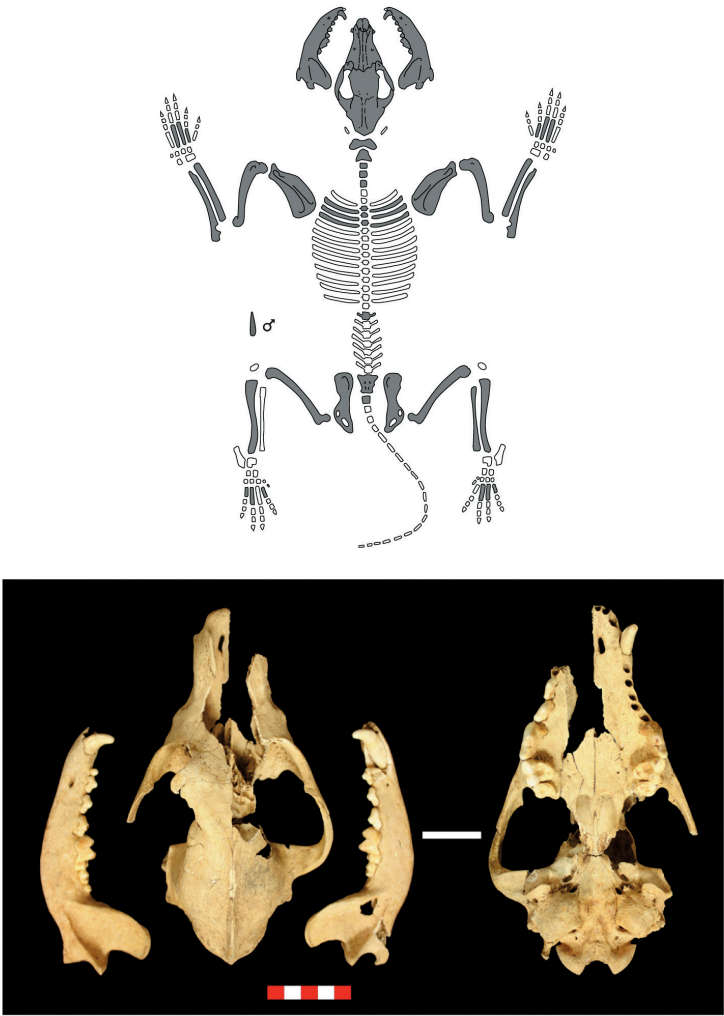

Fig. 13. Representación esquelética del perro n. ${ }^{\circ} 1$ de la fosa de La Velilla (Osorno, Palencia) y detalle del cráneo (en color en la edición electrónica).

neales, nos llevan a descartar su posible correspondencia a un lobo (Canis lupus). Los datos osteométricos obtenidos de estos restos, conforme al protocolo establecido por Driesch (1976), se recogen en el Anexo 1.

El estudio del perro n. ${ }^{\circ}$ 2, representado solo por el cráneo, sin ninguna de las piezas dentales pero con los alveolos abiertos, arroja muy poca luz sobre su edad (adulto de más de 18 meses) y complexión (mesomorfo), y ninguna sobre su sexo y posibles patologías (Fig. 14). Pero, a cambio, proporciona información reveladora sobre el desollado del cadáver del animal, y contribuye a formular preguntas interesantes sobre las circunstancias en que su cráneo llegó a la fosa y sobre su significado.

A diferencia del perro $n .^{\circ} 1$, sin marcas de carnicería en el esqueleto que delaten algún tipo de procesado del cuerpo previo a su inhumación, en el cráneo del n. ${ }^{\circ} 2$ cabe apreciar un conjunto de incisiones, paralelas entre sí y de hasta $17 \mathrm{~mm}$ de longitud, que se concentran en el parietal y en el temporal del eurion derecho. Son cortes indiscutiblemente antrópicos cuya particular disposición, parecen reflejar un despellejado o, en un proceso de despiece, la desarticulación de las mandíbulas. No puede descartarse que guarden relación con un aprovechamiento cárnico del animal, pero hasta el momento no se conocen en la península ibérica testimonios de consumo de carne de perro con anterioridad a la Edad del Bronce (Sanchís y Sarrión 2004; Liesau et al. 2014).

Pero, además, el cráneo de este animal ofrece la particularidad de mostrar una coloración y una tersura distintas de las de los huesos del perro n. ${ }^{\circ} 1$, hecho que, unido a la presencia de ciertas fracturas antiguas en ambos cigomáticos y a la ausencia de dientes y mandíbulas, revela que la fosa de enterramiento no fue su primer contexto de depósito. A diferencia de la inhumación humana y de la del perro $\mathrm{n}^{\circ}{ }^{1}$, se trata, pues, de un depósito secundario. Una posibilidad a contemplar es que el cráneo, ya mondo, hubiera llegado accidentalmente al hoyo acompañando a aquellos pocos huesos de vaca y oveja, rodados, rotos e inconexos a los que nos referimos inicialmente. Sin em-
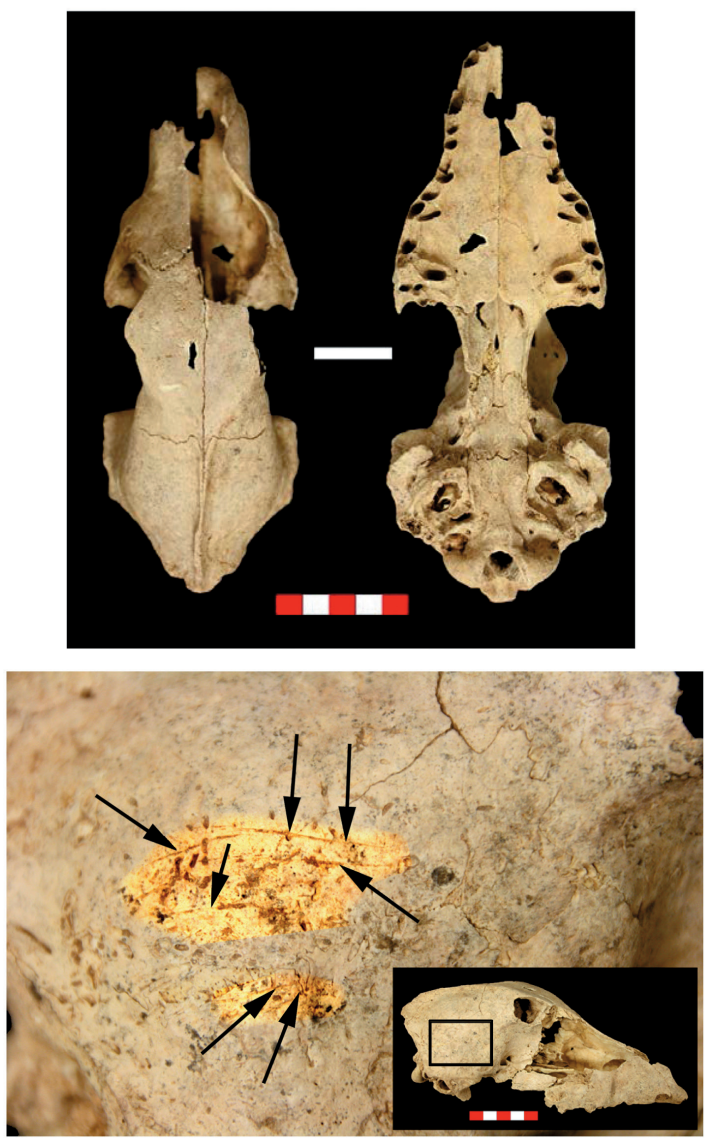

Fig. 14. Cráneo del perro n. ${ }^{\circ} 2$ de la fosa de La Velilla (Osorno, Palencia) y detalle de las marcas de carnicería en su eurion derecho (abajo) (en color en la edición electrónica). 
bargo, la frecuencia de cráneos sueltos de canes en depósitos rituales calcolíticos obliga a tener en cuenta la posibilidad de que la llegada del cráneo del perro $\mathrm{n}^{\circ} 2$ a la fosa funeraria fuese resultado de un gesto simbólico deliberado y perfectamente calculado. Un testimonio contundente es el depósito del área 40 de Camino de las Yeseras, con seis cabezas, algunas todavía provistas de sus primeras vértebras cervicales (Daza Perea 2011: 213-214), y otro comparable el hoyo del yacimiento vallisoletano de Los Cercados, con tres cráneos que acompañan a otras tantas cabezas humanas, una de estas decapitada (García Barrios 2007).

¿Tal vez se quiso reunir en la tumba de la mujer de La Velilla al perro de su propiedad en el momento de morir y a otro can del que también había sido dueña mucho tiempo antes? ¿O el gesto tuvo como objetivo homenajear al perro enterrado junto a la difunta trasladando a su lado los restos de un viejo compañero o de alguno de sus progenitores? ¿Procedería el cráneo, en cualquier caso, de una auténtica "sepultura de perro", con el cuerpo de animal completo -en la submeseta norte las hay en los campos de hoyos de Los Doce Cantos, La Calderona, Pozo Nuevo y Las Peñas ${ }^{2}$ - o de un depósito con solo restos parciales como los ya mencionados de Yeseras y Mucientes? Más preguntas sin respuesta de las deseadas pero no por completo inútiles porque al menos ilustran un hecho cada vez mejor documentado: que muchos de los pozos de los "campos de hoyos" fueron comúnmente objeto de reapertura, lo que significa que contaban con algún tipo de señalización.

\subsection{La cronología de las fosas calcolíticas y el inicio de la 'postvida' de los megalitos de Los Zumacales y La Velilla}

Las dataciones de las tumbas de La Velilla y Trascabañas confirman la cronología dentro de la primera mitad del III milenio de los enterramientos individuales en fosa de la Edad del Cobre en la cuenca del Duero (Fig. 15). Pero además, debido a su proximidad a los megalitos de Los Zumacales (Alonso Díez et al. 2015) y La Velilla, tienen el interés de orientarnos sobre cuándo tuvo lugar el declive del Megalitismo en dicho sector, al entender que la implantación del nuevo modelo de sepultura solo pudo producirse cuando los grandes mausoleos cesaron en la función funeraria que originalmente animó su construcción. De ahí que

\footnotetext{
2 García Barrios, A. S. Los inicios de la Edad del Cobre en el valle medio del Duero: una aproximación a los modos de vida en el centro de la Meseta en los albores de la metalurgia. Tesis Doctoral, inédita, defendida en la Facultad de Filosofía y Letras de la Universidad de Valladolid, 2006.
}

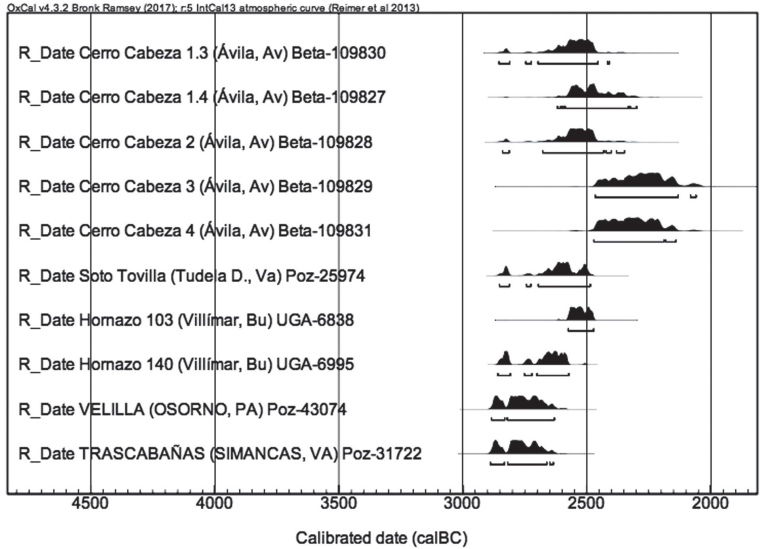

Fig. 15. Dataciones C-14 de enterramientos en fosa del Cobre Precampaniforme en la cuenca del Duero. AV Ávila, BU Burgos, PA Palencia, VA Valladolid. OxCal v 4.3.2 Bronk Ramsey (2017); r.5; IntCal 13 datos atmosféricos a partir de Reimer et al. (2013).

veamos en ello una oportunidad para analizar el proceso por el que las comunidades de la Edad del Cobre instaladas en los antiguos territorios megalíticos dejaron de enterrar a sus muertos en el panteón familiar monumental y adoptaron fórmulas funerarias alternativas. En definitiva, de acuerdo con las teorías de C. Holtorf (1997, 1998), nuestras sepulturas constituirían un testimonio indirecto del inicio de la 'postvida' de Los Zumacales y La Velilla, un nuevo capítulo en sus biografías: en la Edad del Cobre los dólmenes, gracias a su sacralidad y prestigio remanentes, seguramente continuaron siendo hitos relevantes en el paisaje y en el imaginario colectivo, aunque ya no cumplieran la función que les correspondió en origen y que alentó su existencia en lo que se considera su "fase clásica" (Álvarez Vidaurre 2006: 118).

En términos conceptuales, distinguir entre 'vida' y 'postvida' megalíticas no plantea problemas, pero en la práctica, cuando se aplica a biografías dolménicas concretas, los límites pueden desdibujarse. La dificultad, en todo caso, es mínima cuando el final del ciclo genuinamente megalítico se acompaña de una destrucción de las arquitecturas (Andrés 2000), bien mediante fuego, como las tumbas calero sorianas (Rojo et al. 2010), bien por demolición, como los buenos ejemplos del sepulcro de corredor alavés de San Martín (Maluquer de Motes 1973; López Calle e Ilarraza 1997) y, aún más ostensiblemente, del soriano de Alcubilla de las Peñas (Rojo et al. 2015: 136-140). Tampoco muestra mayor dificultad cuando el fin del uso conlleva una condena de las entradas, un concienzudo sellado o macizado de los corredores en evitación de cualquier nueva utilización, como se aprecia -de nuevo un testimonio de las tierras interiores de la península- en el 
pasillo de acceso del sepulcro burgalés de El Moreco (Narvarte 2005; Delibes 2010: 42).

Tal vez sea cierto, como sostiene Masset (2002: 12), que todos los sepulcros dolménicos sin excepción sufrieron condena en algún momento de su trayectoria, pero ni en Los Zumacales ni en La Velilla existen pruebas de ello tan incuestionables como las arriba descritas. No se puede descartar, entonces, que lo ocurrido en ambos casos fuera un simple abandono de los monumentos sin colapso de sus arquitecturas, lo que reduce las posibilidades de fijar el punto de partida de la afterlife al estudio de la temporalidad de los osarios. En este sentido las treces dataciones AMS de La Velilla resultan bastante reveladoras: el monumento, cuyo osario permaneció activo durante cerca de medio siglo, comenzó a recibir inhumaciones en el intervalo 3627 3375 cal BC, y decayó como tal calavernario entre 3001-2877 cal BC B $^{3}$ Este último momento constituye, por tanto, el punto de partida de su afterlife y en absoluto parece casual que la fecha obtenida para la tumba en fosa que estudiamos -un nuevo modelo de sepultura para nuevos tiempos- se sitúe, como vimos, en un momento justo posterior a la última utilización del megalito: 2821-2632 cal BC, al $75 \%$ de probabilidad. Es difícil saber si la introducción del nuevo ritual funerario fue respuesta a una crisis de religiosidad, a una saturación del viejo panteón familiar, al fin del dolmen como símbolo de cohesión grupal o a cualquier otra circunstancia de las que con frecuencia se invocan para explicar el colapso dolménico (Tejedor Rodríguez 2015: 484); lo único seguro, una vez advertida la presencia de enterramientos calcolíticos en su entorno inmediato, es que en La Velilla el ocaso del dolmen nada tuvo que ver con el abandono o la despoblación de la campiña del Valdavia.

Según moderna revisión, en Los Zumacales, el NMI de los inhumados es de 14, 9 adultos y 5 inmaduros $^{4}$, se dispone de solo cuatro dataciones C14, una pretumular sobre resto de fauna $(4330-3980 \mathrm{cal} \mathrm{BC})$ y tres $(4065-3365,4070-3370$ y 4040-3340 cal BC) sobre huesos humanos procedentes de la cámara (Alonso Díez et al. 2015: 28). Adolecen del problema de presentar desviaciones muy altas, pero su mayor inconveniente es que conciernen a solo una quinta parte del total de las personas inhumadas lo que impide conocer con exactitud la duración de la trayectoria del sitio. La primera de las fechas apunta a la construcción del megalito en el último tercio del $\mathrm{V}$ milenio, y el

\footnotetext{
3 Zapatero Magdaleno, P. y Esparza Arroyo, A. (e. p.): "Continuidad o ruptura? Sobre la trayectoria de uso de la tumba de La Velilla a través de las fechas radiocarbónicas y el ritual funerario". En BSAA Arqueología LXXXIV.

${ }^{4}$ A. Santa Cruz del Barrio. Análisis antropológico de los restos óseos del sepulcro megalítico de Los Zumacales (Simancas, Valladolid). Trabajo Fin Máster de Antropología Física y Forense. Universidad de Granada, 2016.
}

resto revela que tres de los catorce individuos del osario fueron depositados en el intervalo 4070-3340 cal $\mathrm{BC}$; no se disipa la duda, sin embargo, de si alguno de los nueve cadáveres restantes fue enterrado con posterioridad a dicho intervalo, tal vez al tiempo que los últimos de La Velilla. Nuestra impresión al respecto, basada en el arcaísmo de los proyectiles de sílex del ajuar de Los Zumacales -exclusivamente geométricos, sin los foliáceos presentes en la tumba palentina (Alonso Díez et al. 2015; Zapatero 2015)- es que el dolmen vallisoletano se abandonó todo lo más al final del referido intervalo 4070-3340 cal BC, unos quinientos años antes, por tanto, del colapso de La Velilla, lo cual significaría que el enterramiento de la fosa de Trascabañas fue realizado medio milenio después del abandono de Los Zumacales.

En conclusión, las fosas individuales de La Velilla y Trascabañas, posteriores a los calavernarios de los dólmenes inmediatos, suponen un claro punto de inflexión en los ritos mortuorios de las comunidades prehistóricas de la cuenca media del Duero. Responden a un modelo de tumba, generalizado a partir del Calcolítico, por medio del cual -aunque se siga contemplando algún movimiento de huesos y circulación de reliquias- se sellan los cadáveres, se los aísla en la tierra, y se crea una distancia entre el muerto y los vivos. Todo ello representa una considerable diferencia respecto al modelo de osario abierto y accesible propio de los sepulcros megalíticos, con los huesos exentos y expuestos a un traslado, revelando que a comienzos del III milenio los dólmenes de Osorno y Simancas ya transitaban por su afterlife. Las series de dataciones absolutas de estos dos monumentos, sin embargo, denotan que su declive seguramente no fue simultáneo -el osario de La Velilla se habría iniciado más tarde y habría permanecido operativo varios siglos más que el vallisoletano- lo que constituye una llamada de atención sobre el riesgo de extrapolar, con solo los datos de un caso de estudio, la temporalidad de la "fase clásica" del Megalitismo a todo un territorio.

\section{AGRADECIMIENTOS}

A la Junta de Castilla y León por habernos autorizado a trabajar con los materiales de La Velilla; a los miembros de la empresa Strato SL por permitirnos utilizar datos de su informe inédito sobre la excavación de La Velilla (Osorno, Palencia); a J. J. Fernández González y F. J. Pérez Rodríguez por la ayuda que nos prestaron en el Museo de Palencia; y a Á. Rodríguez González y Francisco Tapias López por los dibujos de los materiales arqueológicos y la preparación de las ilustraciones.

Trab. Prehist., 76, N. ${ }^{\circ} 2$, julio-diciembre 2019, pp. 236-253, ISSN: 0082-5638

https://doi.org/10.3989/tp.2019.12235 


\section{ANEXO}

En la versión electrónica de este artículo, disponible en libre acceso en la página web de la revista, se incluyen como anexo las biometrías de los restos de Canis del hoyo I-J/88-89 de La Velilla (Osorno, Palencia).

\section{BIBLIOGRAFÍA}

Albizuri, S.; Fernández, M. y Tomás, X. 2011: "Evidencias sobre el uso del perro en la carga durante el Bronce Inicial en la Península Ibérica: el caso de Can Roqueta II (Sabadell, Barcelona)". Archaeofauna 20: 139-155.

Aliaga Almela, R. 2008: "El mundo funerario calcolítico en la Región de Madrid". Cuadernos de Prehistoria y Arqueología de la Universidad Autónoma de Madrid 34: 23-39.

Alonso Díez, M., Delibes, G. y Santiago, J. 2015: "El sepulcro megalítico de Los Zumacales, en Simancas (Valladolid)". En Conocer Valladolid 2014. VIII Curso de Patrimonio Cultural. Real Academia de Bellas Artes de la PurísimaConcepción. Valladolid: 13-36.

Álvarez Vidaurre, E. 2006: "Percepción y reutilización de monumentos megalíticos durante la Prehistoria Reciente: el caso de Navarra". Cuadernos de Arqueología de la Universidad de Navarra 14: 117150.

Andrés Rupérez, M. T. 2000: "El espacio funerario dolménico: abandono y clausura". Salduie I: 59-76.

Arnáiz, M. A.; Pascual, S. y Rojo, A. V. 1997: "Los semejantes y los otros: la sepultura múltiple simultánea de Villayerno-Morquillas, Burgos. Nota preliminar". Boletín del Seminario de Estudios de Arte y Arqueología LXIII: 49-69.

Barrett, J. C. 1988: "The living, the dead and the ancestors. Neolithic and Bronze Age mortuary practices". En J. C. Barrett e I. A. Kinnes (eds.): The Archaeology of context in the Neolithic and Bronze Age: recent trends. Department of Archaeology and Prehistory University of Sheffield. Sheffield: 30-41.

Blanco-González, A. 2014: “Rutinas caseras o fiestas comunitarias? Tafonomía y remontaje de la cerámica calcolítica de El Ventorro (Madrid)". Complutum 25: 89-108.

Bradley, R. 1998: The significance of monuments. On the shaping of human experience in Neolithic and Bronze Age Europe. Routledge. London

Bronk Ramsey, C. 2017: "Methods for Summarizing Radiocarbon Datasets". Radiocarbon, 59 (2): 1809-1833.

Brotherton, P.; Haak, W.; Templeton, J.; Brandt, G.; Soubrier, J. y Adler, C. J. 2013: "Neolithic mitochondrial haplogroup H genomes and the genetic origins of Europeans". Nature Communications 4: 1764

Buckberry, J. L. y Chamberlain, A.T. 2002: "Age estimation from the auricular surface of the ilium: a revised method". American Journal of Physical Anthropology 119: 231-239

Buikstra, J. y Ubelaker, D. (eds.) 1994: Standards for data collection from human Skeletal remains: proceedings of a seminar at the Field Museum of Natural History, organized by J. Haas. Arkansas Archeological Survey Research Series 44, Arkansas Archeological Survey. Fayetteville.

Burt, N. M.; Semple, D.; Waterhouse, K. y Lovell, N. C. 2013. Identification and interpretation of joint disease in paleopathology and forensic anthropology. Charles C Thomas Publisher. Springfield.

Capasso, L.; Kennedy, K. A. y Wilczak, C. A. 1999: Atlas of occupational markers on human remains 3. Edigrafital. Teramo.

Cardoso, S.; Alfonso-Sanchez, M. A.; Valverde, L.; Odriozola, A.; PerezMiranda, A. M.; Peña, J. A. y Pancorbo, M. M. de 2011: "The maternal legacy of Basques in northern Navarre: New insights into the mitochondrial DNA diversity of the Franco-Cantabrian area". American Journal of Physical Anthropology 145(3): 480-488 https://doi: 10.1002/ajpa.21532
Carmona Ballestero, E. 2011: "El registro funerario de Fuente Celada (Burgos): prácticas funerarias de las comunidades calcolíticas de la Meseta Norte". Estat critic: Revista d'Arqueologia 5(1): 502-507.

Carmona Ballestero, E. 2013: El Calcolítico en la Cuenca Media del Arlanzón (Burgos, España). Comunidades campesinas, procesos históricos y transformaciones. British Archaeological Reports International Series 2559, Archaeopress. Oxford.

Carmona Ballestero, E.; Valdivielso Gutiérrez, E.; Pascual Blanco, S. y Vega y Miguel, J. J. 2013: "Restos humanos, contextos funerarios y diversidad formal. Los yacimientos calcolíticos de El Hornazo y El Túmulo IL.C1 de Cótar (Burgos)". Revista Atlántica-Mediterránea de Prehistoria y Arqueología Social 15: 53-80.

Davis, S. J. M. y Valla, F. R. 1978: "Evidence for the domestication of the dog 12.000 years ago in the Natufian of Israel". Nature 276: 608-610.

Daza Perea, A. 2011: "Los depósitos de perros en Camino de las Yeseras”. En C. Blasco, C. Liesau y P. Ríos (eds.): Yacimientos calcolíticos con Campaniforme de la región de Madrid: nuevos estudios. Patrimonio Arqueológico de Madrid, 6. Universidad Autónoma de Madrid. Madrid: 211-222.

Delibes de Castro, G. 1987: "Sobre los enterramientos del grupo campaniforme de Ciempozuelos: diversidad y tradición”. En M. Fernández-Miranda (ed.): El origen de la metalurgia en la Península Ibérica II. Fundación José Ortega y Gasset. Oviedo: 37-51.

Delibes de Castro, G. 2010: "La investigación de las sepulturas colectivas monumentales del IV milenio A.C. en la Submeseta Norte española. Horizonte 2007”. En J. Fernández Eraso y J. A. Mujika Alustiza (eds.): Actas del Congreso Internacional sobre Megalitismo y otras manifestaciones funerarias contemporáneas en su contexto social, económico y cultural. Munibe, supl. 32, Sociedad de Ciencias Aranzadi. San Sebastián: 12-56.

Delibes de Castro, G. 2014: "El Calcolítico en la Meseta y su orla atlántica: intensificación económica y avance de la vida sedentaria (3200-2500 cal. AC)". En M. Almagro Gorbea (ed.): Protohistoria de la Península Ibérica: del Neolítico a la Romanización. Universidad de Burgos-Fundación Atapuerca. Burgos: 95-112.

Delibes de Castro, G. y Zapatero Magdaleno, P. 1996: "De lugar de habitación a sepulcro monumental: una reflexión sobre la trayectoria del yacimiento neolítico de La Velilla, en Osorno (Palencia)". En Actas del I Congrés del Neolític a la península Ibèrica (Gavà - Bellaterra 1995). Rubricatum 1, 2: 337-348.

Díaz del Río, P. 2001: La formación del paisaje agrario. Madrid en el III y II milenios BC. Serie Arqueología. Paletnología y Etnología, 9, Comunidad de Madrid. Madrid.

Díaz del Río, P.; Consuegra, S.; Peña-Chocarro, L.; Márquez, B.; Sampedro, C.; Moreno, R.; Albertini, D. y Pino, D. 1997: "Paisajes agrarios prehistóricos en la Meseta peninsular: el caso de Las Matillas (Alcalá de Henares, Madrid)". Trabajos de Prehistoria 54 (2): 93-111.

Driesch, A. von den 1976: A guide to the measurement of animal bones from archaeological sites. Peabody Museum Bulletin, 1. Harvard University. Cambridge (Mass.).

Duday, H. 2009: The archaeology of the dead. Lectures in Archaeothanatology. Oxbow Books. Oxford.

Esparza Arroyo, A., Velasco Vázquez, J. y Delibes de Castro, G. 2012: "Exposición de cadáveres en el yacimiento de Tordillos (Aldeaseca de la Frontera, Salamanca). Perspectiva bioarqueológica y posibles implicaciones para el estudio del ritual funerario de Cogotas I". $\mathrm{Ze}$ phyrus 79: 95-128.

Esparza Arroyo, A.; Velasco Vázquez, F. J.; Delibes de Castro, G. y Cruz Sánchez, P. J. 2008: "Historia de un golpe en la cabeza: sobre el enterramiento calcolítico del Hoyo 197 de 'El Soto de Tovilla' (Tudela de Duero, Valladolid)". Boletín del Seminario de Arte y Arqueología: Arqueología LXXIV: 9-48.

Fabián García, J. F. 1995: El aspecto funerario durante el Calcolitico y los inicios de la Edad del Bronce en la Meseta Norte. Acta Salmanticensia 93, Universidad de Salamanca. Salamanca.

Fabián García, J. F. y Blanco González, A. 2012: "Cuatro enterramientos calcolíticos en hoyo del Cerro de la Cabeza (Ávila)". Complutum 23 (1): 99-120.

Fernández Crespo, T. 2016: "El papel del fuego en los enterramientos neolíticos finales/calcolíticos iniciales de los abrigos de la Sierra de 
Cantabria y sus estribaciones (valle medio-alto del Ebro)". Trabajos de Prehistoria 73 (1): 128-146.

García Barrios, A. S. 2007: "Un enfoque de género en la arqueología de la prehistoria reciente del valle medio del Duero: los cráneos femeninos calcolíticos de Los Cercados (Mucientes, Valladolid)". En C. de la Rosa, M. J. Dueñas, M. I. del Val y M. Santo Tomás (eds.): Nuevos enfoques para la enseñanza de la historia. Mujer y género ante el espacio europeo de educación superior. Asociación Cultural Al-Mudayna. Madrid: 41-56.

Gómez Pérez, J. L.; Blasco, C.; Trancho, G. J.; Grueso, I.; Ríos, P. y Martínez-Ávila, M. 2011: "Los protagonistas". En C. Blasco, C. Liesau y P. Ríos (eds.): Yacimientos calcolíticos con campaniforme de la región de Madrid: Nuevos estudios. Col. Patrimonio Arqueológico de Madrid 6. Universidad Autónoma de Madrid. Madrid: 101132.

Harcourt, R. A. 1974: "The dog in Prehistoric and Early Historic Britain". Journal of Archaeological Science 1: 151-175.

Herrán Martínez, J. I. y Rojo Guerra, M. A. 1999: “¿Una nueva tumba en fosa calcolítica? El hallazgo de Colmenares, Portillo (Valladolid, España), y su contexto arqueológico". Estudos Pre-historicos VII: $111-124$.

Hervella, M.; Izagirre, N.; Alonso, S.; Fregel, R.; Alonso, A.; Cabrera, V. M. y Rúa, C. de la 2012: "Ancient DNA from hunter-gatherer and farmer groups from Northern Spain supports a random dispersión model for the Neolithic expansión into Europe". PloS One 7(4): e34417. https://doi:10.1371/journal.pone.0034417

Holtorf, C. J. 1997: "Beyond cronographies of megaliths: understanding monumental time and cultural memory". En A. Rodríguez Casal (ed.): O Neolítico Atlántico e as orixes do megalitismo (Actas do Coloquio Internacional). Universidade de Santiago de Compostela. Santiago de Compostela: 104-114.

Holtorf, C. J. 1998: "The life-histories of megaliths in Mecklenburg Vorpommern (Germany)". World Archaeology 30 (1): 23-38.

Koudelka, F. 1885: "Das Verhältnis der Ossa longa zur Skeletthöhe bei den Säugetieren". Verhandlungen des naturforschung Vereines in Brünn 24: 127-153.

Liesau, C.; Blasco, C.; Ríos, P.; Vega, J.; Menduiña, R.; Blanco, J. F.;... y Gómez, J. L. 2008: "Un espacio compartido por vivos y muertos: El poblado calcolítico de fosos de Camino de las Yeseras (San Fernando de Henares, Madrid)". Complutum 19 (1): 97-120.

Liesau, C.; Esparza, A. y Sánchez Polo, A. 2014: “¿Huesos en la basura o depósito ritualizado? Los perros descuartizados de La Huelga (Dueñas, Palencia)". Zephyrus 74: 89-115.

Lizcano, R.; Cámara, J. A.; Riquelme, J. A.; Afonso, J. A.; Cañabate, L. y Sánchez, A. 1992: "El polideportivo de Martos. Producción económica y símbolos de cohesión en un asentamiento del Neolítico Final en las campiñas del Alto Guadalquivir". Cuadernos de Prehistoria de la Universidad de Granada 16-17, 1991-92: 5-101.

Lomba, J.; López, M.; Ramos, F. y Avilés, A. 2009: "El enterramiento múltiple, calcolítico, de Camino del Molino (Caravaca, Murcia). Metodología y primeros resultados de un yacimiento excepcional". Trabajos de Prehistoria 66 (2): 143- 159.

López Calle, C. e Ilarraza, J.A. 1997: "Condenaciones y remodelaciones. Una respuesta a la estratigrafía de los sepulcros megalíticos de Cameros". En R. de Balbín y P. Bueno (eds.): Actas del II Congreso de Arqueología Peninsular (Zamora 1996). II. Neolítico, Calcolítico y Bronce: $309-321$. Zamora.

Maluquer de Motes, J. 1973: "En torno a la cultura megalítica de la Rioja alavesa". Estudios de Arqueología Alavesa 6: 83-101.

Mann, R. W. y Murphy, S. P. 1990: Photographic regional atlas of bone disease: A guide to pathologic and normal variation in the human skeleton. Charles C Thomas Pub Ltd. Springfield.

Márquez Romero, J. E. 2004: "Muerte ubicua: sobre deposición de esqueletos humanos en zanjas y pozos en la prehistoria reciente de Andalucía”. Mainake XXVI: 115-138.

Martiniano, R.; Cassidy, L. M.; O'Maolduouin, R.; Mclaughlin, R.; Silva, N. M.; Manco, L.;... Bradley, D. G. 2017: "The population genomics of archaeological transition in west Iberia: Investigation of ancient substructure using imputation and haplotypebased methods". PLoS Genet 13(7): e1006852.

https://doi.org/10.1371/journal.pgen.1006852
Masset, C. 2002: "Ce qu' on sait, ou croit savoir, du rôle du feu dans les sépultures collectives néolithiques”. En M. Rojo y M. Kunst (eds.): Sobre el ritual del fuego en los rituals funerarios del Neolítico. Studia Archaeologica 91, Universidad de Valladolid. Valladolid: 9-20.

Mays, S. A. 2006: "A palaeopathological study of Colles fracture". International Journal of Osteoarchaeology 16(5): 415-428.

Mays, S. A. 2008: "Septal aperture of the humerus in a mediaeval human skeletal population". American Journal of Physical Anthropology 136 (4): 432-440.

Morey, D. 2010: Dogs. Domestication and the development of a social bond. Cambridge University Press. Cambridge-New York.

Narvarte, N. 2005: Gestión funeraria dolménica en la cuenca alta y media del Ebro: fases de ocupación y clausuras. Colección HistoriaArqueología 16, Instituto de Estudios Riojanos. Logroño.

Núñez, C.; Baeta, M.; Cardoso, S.; Palencia-Madrid, L.; García-Romero, N.; Llanos, A. y Pancorbo, M. M. de 2016: "Mitochondrial DNA reveals the trace of the ancient settlers of a violently devastated Late Bronze and Iron Ages village". PLoS One 11(5): e0155342. https://doi:10.1371/journal.pone.0155342.

Pääbo, S.; Poinar, H.; Serre, D.; Jaenicke-Despres, V.; Hebler, J.; Rohland, N.; ... Hofreiter, M. 2004: "Genetic analyses from ancient DNA". Annual Reviews of Genetics 38: 645-679.

Palomo Díez, S. 2015: Caracterización genética de las poblaciones de las Edades del Cobre y del Bronce de la Submeseta Norte de la península ibérica. Tesis doctoral. Facultad de Ciencias Biológicas. Universidad Complutense de Madrid. http://eprints. ucm.es/34256/1/T36669.pdf (consulta 9-8-2017).

Pereira, L.; Richards, M.; Goios, A.; Alonso, A.; Albarrán, C.; García, O.; ... Amorim, A. 2005: "High-resolution mtDNA evidence for the late-glacial resettlement of Europe from an Iberian refugium". Genome Research 15(1): 19-24.

Pérez-Romero, A.; Iriarte, E.; Galindo-Pellicena, M. A.; García-González, R.; Rodríguez, L.; Castilla, M.; ... y Carretero, J. M. 2017: “An unusual Pre-bell beaker Copper age cave burial context from El Portalón de Cueva Mayor site (Sierra de Atapuerca, Burgos)". Quaternary International 433: 142-155.

Reimer P. J.; Bard, E.; Bayliss, A.; Beck, J. W.; Blackwell, P. G.; Bronk Ramsey, C.; ... y van der Plicht, J. 2013: "Selection and treatment of data for radio-carbon calibration: an update to the International Calibration (IntCal) criteria". Radiocarbon 55 (4): 1923-1045.

Rojo Guerra, M.; Garrido Pena, R. y García Martínez de Lagrán, I. 2010: "Tombs for the dead, monuments to eternity: the deliberate destruction of megalithic graves by fire in the interior highlands of Iberia (Soria Province, Spain)". Oxford Journal of Archaeology 29 (3): 253-275.

Rojo Guerra, M. A.; Garrido Pena, R.; Tejedor Rodríguez, C.; García Martínez, I. y Alt, K. W. 2015: "El tiempo y los ritos de los antepasados: La Mina y el Alto del Reinoso, novedades sobre el megalitismo en la Cuenca del Duero". Arpi 03 Extra. Homenaje a Rodrigo de Balbín Behrmann: 133-147.

Ruiz García-Vaso, C.; Vázquez Autón, J. M.; Orenes Hernández, M. y Gil Cano, F. 2013. "Los perros que vivieron en la región de Murcia hace 4000 años: nuevos datos sobre tamaños, edad, alimentación y patologías". En Actas del XIX Congreso nacional de Historia de la Veterinaria y X Congreso Iberoamericano (Madrid 2013). Disponible en http://www.historiaveterinaria.org/update/texto-completo-comunicacionperros-calcolitico-francisco-gil-cano-1457373672.pdf (consulta 13-52017).

Ruíz García-Vaso, C.; Vázquez Autón, J. M.; Lomba Maurandi, J.; Avilés Fernández, A.; Haber Uriarte, M.; Orenes Hernández, A. y Gil Cano, F. 2014: "El yacimiento calcolítico 'Camino del Molino' (Caravaca de la Cruz, Murcia): una oportunidad excepcional para estudiar los cánidos que poblaron el sureste español hace 4000 años. Primeros resultados". Origenes y raices 6: 5-7.

Sánchez-Quinto, F.; Schroeder, H.; Ramirez, O.; Avila-Arcos, M. C.; Pybus, M.; Olalde, I.; ... Lalueza-Fox, C. 2012: "Genomic affinities of two 7,000 - year-old Iberian hunter-gatherers". Current Biology 22(16): 1494-1499. https://doi: 10.1016/j.cub.2012.06.005

Sanchís, A. y Sarrión, I. 2004. "Restos de cánidos (Canis familiaris ssp.) en yacimientos valencianos de la Edad del Bronce". Archivo de Prehistoria Levantina XXV: 161-198.

Trab. Prehist., 76, N. . 2, julio-diciembre 2019, pp. 236-253, ISSN: 0082-5638

https://doi.org/10.3989/tp.2019.12235 
Saunders, S. R. y Rainey, D. L. 2008: "Nonmetric trait variation in the skeleton: abnormalities, anomalies and atavisms". En M. A. Katzenberg y S. R. Saunders (eds.): Biological anthropology of the human skeleton. John Wiley \& Sons. Hoboken: 533-560.

Schmitt, A. 2004: "Age-at-death assessment using the os pubis and the auricular surface of the ilium: a test on an identified Asian sample". International Journal of Osteoarchaeology 14: 1-6.

Szécsényi-Nagy, A.; Roth, C.; Brandt, G.; Rihuete-Herrada, C.; TejedorRodríguez, C.; Held, P.; ... Alt, Kurt W. 2017: "The maternal genetic make-up of the Iberian Peninsula between the Neolithic and the Early Bronze Age". Scientific Reports 7: 15644. https://doi: 10.1038/ s41598-017-15480-9

Tejedor Rodríguez, C. 2015: La pervivencia de los usos megalíticos en el valle del Duero/Douro a lo largo de la Prehistoria Reciente (IV-II milenio Cal. BC). Tesis doctoral, Facultad de Letras de la Universi- dad de Valladolid, p. 484. http://uvadoc.uva.es/handle/10324/17998 (consulta 5-1-2018).

Thomas, J. 1991: Rethinking the Neolithic. Cambridge University Press. Cambridge.

Waldron, T. 2008: Palaeopathology. Cambridge University Press. Cambridge.

White, T. y Folkens, P. 2005: Human bone manual. Elsevier Academic Press. London.

Zammit, J. 1991: "Les sépultures préhistóriques et le feu: utilisation rituelle, cremation et incineration". Bulletin de la Société Préhistorique Française 88 (3): 70-72.

Zapatero Magdaleno, P. 2015: El Neolítico en el Noroeste de la Cuenca del Duero: el yacimiento de la Velilla en el Valle del Valdavia (Palencia). Tesis Doctoral, Facultad de Filosofía y Letras. Universidad de Valladolid http://uvadoc.uva.es/handle/10324/13185 (consulta 208-2017) 